\title{
The Development of the
} Mesoprefrontal Dopaminergic
System in Health and Disease

\author{
K. Ushna S. Islam ${ }^{1 \dagger}$, Norisa Meli1,2† and Sandra Blaess ${ }^{1 *}$ \\ ${ }^{1}$ Neurodevelopmental Genetics, Institute of Reconstructive Neurobiology, Medical Faculty, University of Bonn, Bonn, \\ Germany, ${ }^{2}$ Institute of Neuropathology, Section for Translational Epilepsy Research, Medical Faculty, University of Bonn, \\ Bonn, Germany
}

OPEN ACCESS

Edited by:

Jean-Francois Poulin,

McGill University, Canada

Reviewed by:

Leora Yetnikoff,

College of Staten Island,

United States

Raj Awatramani,

Northwestern University,

United States

*Correspondence:

Sandra Blaess

sblaess@uni-bonn.de

†These authors have contributed equally to this work

Received: 24 July 2021 Accepted: 10 September 2021 Published: 12 October 2021

Citation:

Islam KUS, Meli N and Blaess S (2021) The Development of the Mesoprefrontal Dopaminergic System in Health and Disease.

Front. Neural Circuits 15:746582. doi: 10.3389/fncir.2021.746582
Midbrain dopaminergic neurons located in the substantia nigra and the ventral tegmental area are the main source of dopamine in the brain. They send out projections to a variety of forebrain structures, including dorsal striatum, nucleus accumbens, and prefrontal cortex (PFC), establishing the nigrostriatal, mesolimbic, and mesoprefrontal pathways, respectively. The dopaminergic input to the PFC is essential for the performance of higher cognitive functions such as working memory, attention, planning, and decision making. The gradual maturation of these cognitive skills during postnatal development correlates with the maturation of PFC local circuits, which undergo a lengthy functional remodeling process during the neonatal and adolescence stage. During this period, the mesoprefrontal dopaminergic innervation also matures: the fibers are rather sparse at prenatal stages and slowly increase in density during postnatal development to finally reach a stable pattern in early adulthood. Despite the prominent role of dopamine in the regulation of PFC function, relatively little is known about how the dopaminergic innervation is established in the PFC, whether and how it influences the maturation of local circuits and how exactly it facilitates cognitive functions in the PFC. In this review, we provide an overview of the development of the mesoprefrontal dopaminergic system in rodents and primates and discuss the role of altered dopaminergic signaling in neuropsychiatric and neurodevelopmental disorders.

Keywords: prefrontal cortex, innervation, dopamine receptors, neuropsychiatric diseases, ventral midbrain

\section{MESOPREFRONTAL DOPAMINERGIC NEURONS}

Midbrain dopaminergic (mDA) neurons modulate many brain functions including voluntary movement, reward behavior, and cognitive processes (Iversen et al., 2009). Degeneration of a subset of mDA neurons underlies the motor deficits in Parkinson's disease, while altered dopamine (DA) transmission is implicated in neuropsychiatric disorders including depression, schizophrenia, autism, ADHD, and substance abuse (Del Campo et al., 2011; Volkow and Morales, 2015; Grace, 2016; Surmeier et al., 2017; Marotta et al., 2020; Sonnenschein et al., 2020). mDA neurons are located in the ventral midbrain where they form the A8, A9, and A10 group. The A10 neurons are located in the ventral tegmental area (VTA) and linear nucleus (LiN), the A9 neurons in the substantia nigra pars compacta $(\mathrm{SNpc})$ and substantia nigra pars lateralis $(\mathrm{SNl})$, while the A8 group is found in the retrorubral field (RRF). $\mathrm{mDA}$ neuronal projections run through the medial forebrain bundle (MFB) and then diverge into the various forebrain target areas, including dorsal striatum, amygdala, nucleus accumbens, olfactory tubercle, and prefrontal cortex (PFC) 


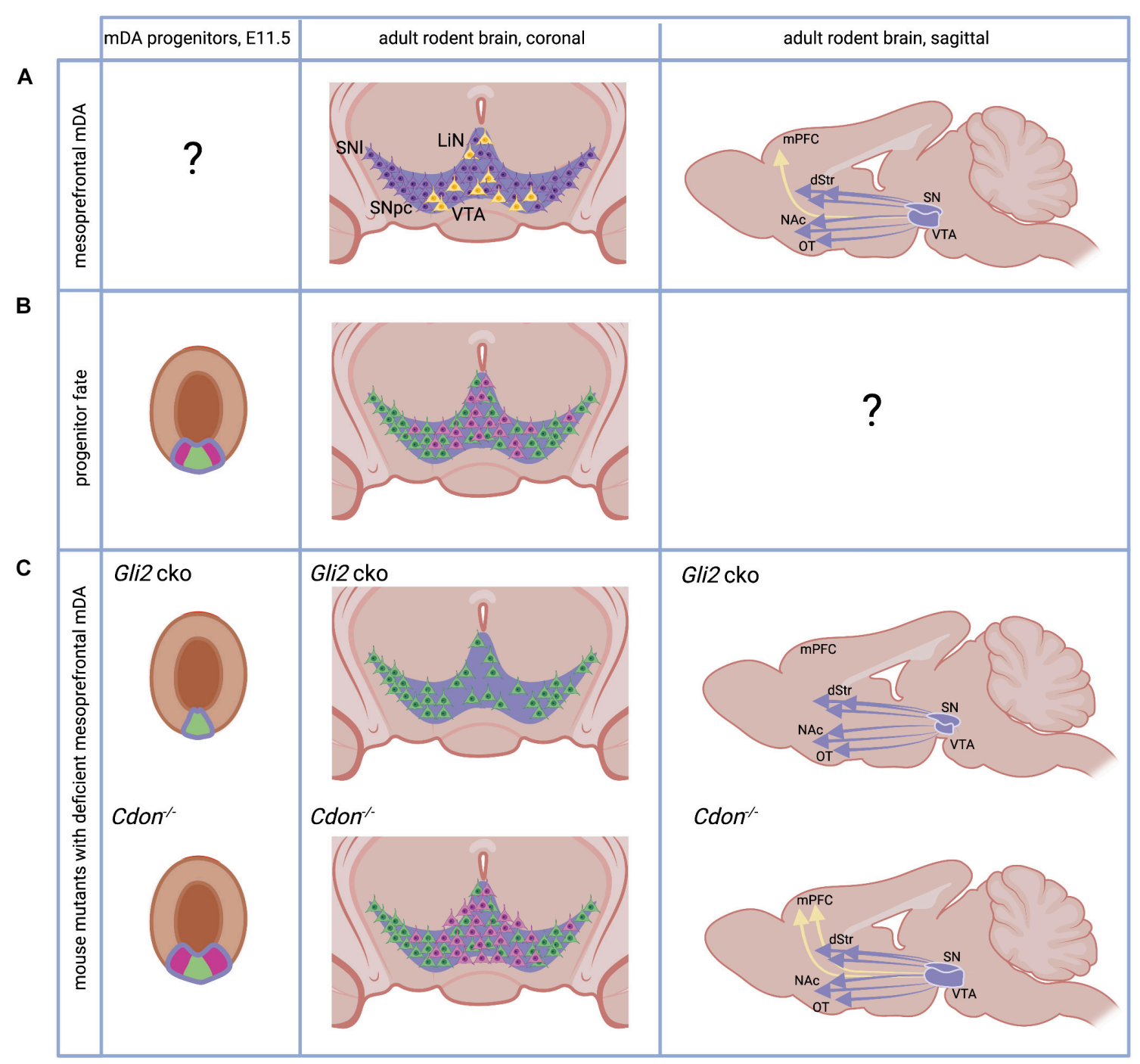

FIGURE 1 | The adult and developing mesoprefrontal DA system in rodents. (A) Localization of mesoprefrontal mDA neurons (yellow) in the adult ventral midbrain (coronal view) and their projections (yellow arrow) to the adult medial PFC (mPFC, sagittal view). Non-mesoprefrontal mDA neurons and projections are in purple. Note that it is unknown whether there are specific mesoprefrontal mDA progenitors (indicated by "?"). (B) The mDA progenitor domain (purple outline) is divided in a medial (green) and lateral (pink) domain based on gene expression. Progenitors from these two domains give rise to mDA neurons with different anatomical location in the adult brain (pink and green neurons in coronal view). Note that it has not been examined whether mDA progenitors from these two domains form specific subcircuits in the DA system (indicated by "?"). (C) Mice with alterations in the SHH signaling pathway have an altered mesoprefrontal DA system. Conditional inactivation of GLI2 (Gli2 cko) results in loss of the lateral progenitor domain, a reduced number of VTA neurons and loss of mesoprefrontal DA projections. Inactivation of CDON (Cdon $\left.{ }^{--}\right)$results in increased proliferation of mDA progenitors, an increased number of VTA neurons and increased DA release in the mPFC. See main text for details. dStr, dorsal striatum, NAc, nucleus accumbens, OT, olfactory tubercle. Created with BioRender.com.

(Iversen et al., 2009; Figure 1A). In recent years, molecularly distinct $\mathrm{mDA}$ subpopulations as well as anatomically and physiologically discrete DA circuits and their effects on various aspects of behavior have been studied in increasing detail, driven by rapid advances in single-cell gene expression profiling, viral tracing systems, DA sensors, and opto- and chemogenetic techniques (e.g., Lammel et al., 2011; Beier et al., 2015; Menegas et al., 2018; Poulin et al., 2018, 2020; Saunders et al., 2018; Engelhard et al., 2019; Lee et al., 2021). Based on these and numerous other studies, it is now evident that the DA system is composed of diverse populations of $\mathrm{mDA}$ neurons and that this diversity is critical for the various functional performances of the DA system. In this review, we focus specifically on the mesoprefrontal DA system, which is formed by $\mathrm{mDA}$ neurons that project to the PFC.

In the adult rodent brain, mesoprefrontal mDA neurons are primarily localized in the medial and ventral VTA region and LiN (Lammel et al., 2011; Yamaguchi et al., 2011; Figure 1A). These mesoprefrontal mDA neurons differ in their molecular profile (e.g., express low levels of dopamine transporter) and in their electrophysiological properties from other mDA neurons, indicating that they form a distinct subclass of $\mathrm{mDA}$ neurons 
(Lammel et al., 2011). This is supported by tracing studies in rodents that show that mesoprefrontal mDA neurons do not send extensive collaterals to other forebrain areas (Aransay et al., 2015; Beier et al., 2019). On a functional level, it has been demonstrated that aversion is encoded by mesoprefrontal mDA neurons while mDA neurons projecting to the nucleus accumbens encode reward. These distinct functions are associated with distinct inputs: aversion-encoding mesoprefrontal $\mathrm{mDA}$ neurons receive inputs from the lateral habenula, while the reward-encoding mDA neurons are activated by inputs from the lateral-dorsal tegmentum (Lammel et al., 2012). It is important to note that a substantial fraction of these mesoprefrontal mDA neurons co-express Slc17a6 (the gene encoding the vesicular glutamate transporter 2, vGLUT2) indicating that they have the ability to corelease the neurotransmitter glutamate (Yamaguchi et al., 2011; Poulin et al., 2018). In the primate brain, the results of a recent viral tracing study in macaques suggest that $\mathrm{mDA}$ neurons in the medial VTA may be the main source of DA innervation to the PFC, whereas lateral VTA or medial SNpc mDA neurons are more likely to send projections to motor and somatosensory cortices (Zubair et al., 2021). An analysis of SLC17A6 expression in marmosets and humans demonstrates that mDA neurons in the lateral VTA and LiN co-express vGLUT2 also in primates, but whether these co-expressing cells are part of the mesoprefrontal DA system is unknown (Root et al., 2016).

At the functional level, decades of research have shown that the mesoprefrontal DA system exerts a profound modulatory function on the PFC and strongly influences PFC-mediated executive functions (i.e., working memory, decision making, behavioral flexibility) and PFC-regulated behaviors (goaldirected behavior, approach-avoidance behavior, response to stress or pain). Since the focus of this review is the development of the mesoprefrontal system, we refer the interested reader to some recent reviews covering the functional aspects of the mesoprefrontal DA system (Weele et al., 2018; Pastor and Medina, 2021; Starkweather and Uchida, 2021).

\section{PREFRONTAL CORTEX IN RODENTS AND PRIMATES}

Before discussing the organization of the mesoprefrontal system and its development in more detail, we will briefly describe how we define the terms PFC and medial PFC (mPFC) in rodents and primates in the context of this review. There is still no consensus on what constitutes the PFC, especially since there is disagreement regarding the subdivisions of prefrontal cortical areas in different species. Functionally, the human PFC is subdivided into dorsolateral, dorsomedial, ventrolateral, ventromedial, and orbital prefrontal cortex. These areas are mostly granular, showing a six-layered laminar organization with a distinct granular layer IV. However, some parts of the primate PFC consist of dysgranular cortex with an indistinct layer IV or agranular cortex in which layer IV is completely absent, such as the anterior cingulate cortex. In contrast, all frontal cortical areas are agranular in rodents, thus lacking the subdivision into granular and dysgranular cortices (Carlén, 2017;
Laubach et al., 2018). Nevertheless, functional data suggest that the prelimbic, infralimbic, and anterior cingulate cortices of rodent frontal cortex have functions that are attributed to the dorsolateral PFC and anterior cingulate cortices in primates (Uylings et al., 2003; Seamans et al., 2008). These regions are classified as prefrontal in rodents. Because these areas are located in the medial frontal cortex in both rodents and primates, they are referred to as the mPFC (Laubach et al., 2018). We therefore use the term mPFC to describe the prelimbic, infralimbic, and anterior cingulate cortex in rodents. The cingulate cortex that extends from the genu of corpus callosum caudally, the anatomical region immediately posterior to the $\mathrm{MPFC}$, is referred to as caudal cingulate cortex in our review. For studies in primates and rodents in which the prefrontal subregions are not specified in terms of the above definitions, we followed the terminologies used in the original publications.

\section{DEVELOPMENT OF THE PREFRONTAL CORTEX}

The cerebral cortex exhibits an orderly laminar organization that is established during embryonic development. While the PFC is the last cortical area to fully mature in terms of inputs and local microcircuits, there is no clear evidence that the timing of early cortical development (neurogenesis, layer formation) is markedly different from other cortical areas. Two recent reviews have discussed in detail the development of the PFC in anatomical and functional terms (Schubert et al., 2015; Chini and HanganuOpatz, 2020). The basic steps of corticogenesis are summarized in Supplementary Figure 1.

In the next paragraphs, we will focus on the development of the mesoprefrontal DA system in rodents and primates. For a detailed account of the general development of the rodent DA system see the following reviews (Blaess and Ang, 2015; Brignani and Pasterkamp, 2017; Ásgrímsdóttir and Arenas, 2020).

\section{THE DOPAMINERGIC PROGENITOR DOMAIN - SPECIFIC PROGENITORS FOR MESOPREFRONTAL DOPAMINERGIC NEURONS?}

Midbrain dopaminergic neurons develop from progenitors in the floor plate of the ventral midbrain. The floor plate, located in the ventral midline of the neural tube, is different from the surrounding neuroepithelia tissue in the neural tube since: (1) its lineage diverges from the neuroepithelia fate quite early, and (2) it serves as one of the organizing centers in the development of the midbrain, by secreting the ventralizing factor Sonic Hedgehog (SHH) (Bodea and Blaess, 2015). The expression of Shh in the midbrain floor plate is dynamic (Joksimovic et al., 2009; Blaess et al., 2011; Hayes et al., 2011). Initially, around E8.0 in mice, Shh is expressed only in the notochord, a mesodermal structure underlying the ventral neural tube. Cells in the midline of the forming neural tube respond to $\mathrm{SHH}$ signaling. This response can be visualized by the presence of Gli1, a transcription 
factor in the SHH signaling pathway only expressed in cells that receive high levels of $\mathrm{SHH}$ signaling. SHH-responding cells are specified into floor plate cells, characterized by the expression of the transcription factor FOXA2 (Forkhead box A2). The FOXA2-positive floor plate cells stop responding to $\mathrm{SHH}$ signaling but start to secret $\mathrm{SHH}$ themselves and induce floor plate fate in neighboring cells. This process continues until E10.5, when the middle third of the ventral midbrain has been transformed into FOXA2-expressing cells. Within the floor plate domain, the medial area expresses the transcription factor LMX1A (LIM homeobox transcription factor 1 alpha) and this is the region that eventually gives rise to $\mathrm{mDA}$ neurons (Andersson et al., 2006; Figure 1B). This LMX1A-expressing domain can be further subdivided into a medial and lateral domain based on gene expression. For example, it has been shown that OTX2 (Orthodenticle Homeobox 2) and NOLZ1 (also known as ZNF503) are restricted to the lateral domain, while SOX6 (sex determining region Y (SRY)-box 6) is expressed in medial progenitors (Panman et al., 2014; Figure 1B). Fatemapping studies of medial and lateral domain progenitors come to conflicting results about their contribution to different anatomical domains of the DA system in the adult brain (Poulin et al., 2020), but several lines of evidence suggest that the medial progenitor domain is biased to give rise to neurons of the SNpc and the lateral VTA while the lateral progenitor domain gives rise to the medial VTA (Blaess et al., 2011; Hayes et al., 2011; Panman et al., 2014; Figure 1B). SHH signaling is essential for the induction of the mDA progenitor domain, but $\mathrm{SHH}$ signaling is required longer for induction of the lateral progenitor domain than for induction of the medial domain. This is evident from Gli1 expression, the above-mentioned readout for high-level $\mathrm{SHH}$ signaling, which is downregulated first in the medial and then in the lateral domain. Thus, conditional inactivation of the transcription factor GLI2 downstream of the $\mathrm{SHH}$ pathway in the midbrain around E8.5 (Gli2 conditional ko mice) essentially abolishes $\mathrm{SHH}$ signaling activity in the ventral midbrain. Since the medial domain no longer requires $\mathrm{SHH}$ for its induction at this time point, it is formed, albeit at a smaller size. In contrast, the lateral mDA progenitor domain is almost completely absent. In the brain of adult Gli2 conditional ko mice, the number of mDA neurons in the medial VTA is severely reduced and projections to the $\mathrm{MPFC}$ are absent, while projections to other VTA or SNpc target areas are not overtly reduced (Kabanova et al., 2015; Figure 1C). Interestingly, inactivation of the gene encoding CDON (Cell adhesion molecule-related/downregulated by oncogenes), a co-receptor of the $\mathrm{SHH}$ receptor Patched 1 that modulates $\mathrm{SHH}$ pathway activity and is expressed in mDA progenitors, leads to the opposite result: the number of proliferating $\mathrm{mDA}$ progenitors is increased and so is the number of mDA neurons in the VTA in the adult brain. The number of $\mathrm{mDA}$ neurons in the $\mathrm{SN}$ is not significantly altered. The increase in VTA-mDA neurons goes along with increased DA release and a higher number of DA presynaptic sites in the $\mathrm{MPFC}$, an effect that is not observed in other target areas of the VTA (Verwey et al., 2016; Figure 1C). Importantly, the function of $\mathrm{SHH}$ signaling in cell fate specification in the ventral midbrain can be largely pinpointed to its role in $\mathrm{mDA}$ progenitors. GLI transcription factors, which are essential for $\mathrm{SHH}$ downstream signaling, are not expressed in differentiated mDA neurons and accordingly Gli1, the readout for the activated pathway, is not detected in differentiated mDA neurons (Mesman et al., 2014). In summary, these studies suggest that $\mathrm{SHH}$ signaling is required after E8.5 in the developing mouse brain to induce the lateral $\mathrm{mDA}$ progenitor domain and that this domain contains the progenitors that give rise to mesoprefrontal $\mathrm{mDA}$ neurons.

\section{DIFFERENTIATION ONSET OF MIDBRAIN DOPAMINERGIC NEURONS - LATE BIRTH DATE OF MESOPREFRONTAL DOPAMINERGIC NEURONS?}

In mouse, cell cycle exit of mDA neurons starts at around E10 and continues until about E14.5 (Bayer et al., 1995; Bye et al., 2012). Expression of tyrosine hydroxylase (TH), the rate limiting enzyme of the DA synthesis pathway is first observed between E10 and E10.5 (Dumas and Wallén-Mackenzie, 2019). Besides the evidence for spatial distinct progenitor domains described in the previous paragraph, there is also evidence that specific mDA subpopulations differ in their birth date (i.e., differentiation onset). In mice, the peak of cell cycle exit occurs earlier for mDA neurons of the SNpc (around E10.5) than for the ones forming the VTA (around E11.5). This peak is shifted to an even later time point (E13.5) for the interfascicular nucleus in the ventromedial VTA (Bayer et al., 1995; Bye et al., 2012). A similar temporal sequence in $\mathrm{mDA}$ differentiation onset has been described in rat: SNpc neurons are born between E12.5 and E15.5, with a peak at E12.5; mDA neurons of the lateral VTA are born in the same period but with a peak at E13.5; and those of the medial VTA are generated between E13.5 and E16.5 with a peak around E15.5 (Altman and Bayer, 1981). Since mesoprefrontal mDA neurons are mostly located in the medial and ventral VTA in rodents (Yamaguchi et al., 2011), this could suggest that these neurons are born later than other mDA neurons. In primates, the development of the catecholaminergic system starts early in embryonic development and the onset of SNpc neuron generation is also earlier than the one for VTA neurons. In rhesus monkey, mDA neurons are detected during the first quarter of gestation [5-6 gestational weeks (gw)]. mDA neurons in the SNpc are generated first, between E36-E43, followed by mDA neurons in the VTA (E38-E43) (Levitt and Rakic, 1982). In humans, distinct TH-expressing cell populations can be detected along the rostrocaudal axis of the brain already at $6 \mathrm{gw}$ (Freeman et al., 1991; Verney et al., 1991; Zecevic and Verney, 1995). At this stage, prominent regions with dense clusters of TH-expressing cells are found in the mesencephalon probably representing the anlage of the three different midbrain $\mathrm{mDA}$ groups: A8 caudally, A9 laterally, and A10 medially (Figure 2). Generally, the sequence of these early events in the developing DA system in rodents and primates are remarkably similar. However, the timing of these events is not synchronized across these species, considering their respective gestational lengths. 


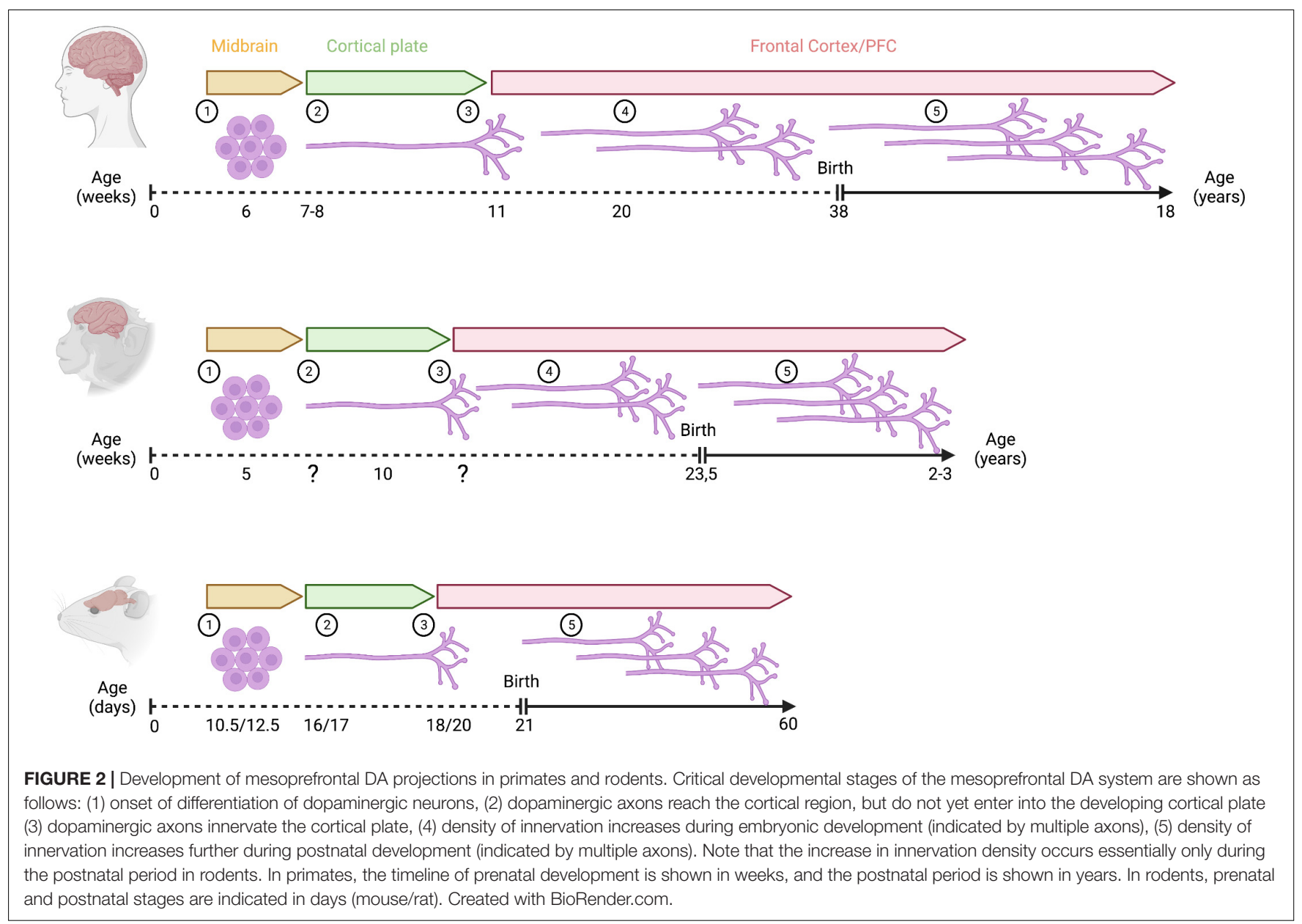

Based on a study that equates neurodevelopmental stages across mammalian species (Clancy et al., 2001), $6 \mathrm{gw}$ in humans and $5 \mathrm{gw}$ in macaques are considered earlier gestational timepoints than E10.5 in mice and E12.5 in rats (Supplementary Figure 1). Thus, the first appearance of $\mathrm{TH}$-expressing neurons seems to occur earlier in primates than in rodents.

While these rodent and primate data indicate that $\mathrm{mDA}$ neurons in SNpc, lateral, and medial VTA differ in their onset of differentiation, there is as yet no clear evidence that birth date also correlates with mDA subpopulations with specific projection targets (e.g., in mice, are all mesoprefrontal mDA neurons born after E13.5, or all $\mathrm{mDA}$ neurons projecting to the nucleus accumbens born before E13.5?). Moreover, it is not known whether mesoprefrontal mDA neurons (and other mDA subpopulations defined by their projection targets) can be characterized by a particular gene expression profile (Poulin et al., 2020). Slc17a6, the gene encoding vGLUT2, is expressed in a subset of mesoprefrontal mDA neurons in the adult rodent brain but is not in itself a marker for this subset, as it is also expressed in a subpopulation of nucleus accumbensprojecting VTA-mDA neurons and in SNl-mDA neurons projecting to the tail of the striatum (Yamaguchi et al., 2011; Poulin et al., 2018). Interestingly, Slc17a6 is broadly expressed in $\mathrm{mDA}$ neurons during development and only gets restricted to the above-mentioned mDA subtypes in the postnatal brain (Steinkellner et al., 2018; Dumas and Wallén-Mackenzie, 2019; Kouwenhoven et al., 2020). The expression of Slc17a6 in mesoprefrontal mDA neurons in the adult mouse brain is consistent with data showing that a subset of these mDA neurons co-release glutamate in the PFC. This glutamate release primarily leads to the excitation of cortical interneurons (Kabanova et al., 2015; Mingote et al., 2015; Pérez-López et al., 2018; Zhong et al., 2020).

This restricted effect of $\mathrm{mDA}$-mediated glutamate release on GABAergic interneurons, and in particular on a subset of fast-spiking interneurons, could contribute to the refinement of local PFC circuit function. One important component of the protracted functional remodeling process of the PFC during postnatal development is the maturation of these local circuits. This is thought to be largely driven by the maturation of GABAergic interneurons. These changes ultimately lead to the fine-tuning of the excitatory-inhibitory balance in the PFC, which is essential for its normal function (Caballero and Tseng, 2016). Rapid activation of GABAergic interneurons by mDAmediated glutamate release could lead to the rapid inhibition of projection neurons in the PFC and regulate the sparseness and precision of their activation, thus acutely modulating the excitatory-inhibitory balance in PFC neuronal networks. In 
contrast, the long-term processing dynamics of local circuits in the PFC could be modified by the long-lasting effect of DA. This target specificity of the glutamate effect is consistent with the results of a study in which it was shown that electrical stimulation in the VTA leads to glutamate-dependent feed-forward activation of interneurons in the PFC, whereas a form of DA-induced potentiation occurs over a much longer period (Lavin et al., 2005).

\section{DEVELOPMENT OF THE MESOPREFRONTAL DOPAMINERGIC PROJECTIONS IN RODENTS}

Several studies in rodents have followed the development of mDA projections and innervation of their forebrain targets by means of antibody labeling, directed either against DA or TH. Before we start to describe the development of $\mathrm{mDA}$ fibers in the PFC, it is necessary to briefly discuss the expression of DA and TH, the primary markers that have been used for this analysis. TH is the rate-limiting enzyme in DA synthesis and thus a marker for $\mathrm{mDA}$ neurons. Since DA is the direct precursor of noradrenaline, $\mathrm{TH}$ and DA are also present in noradrenergic (NA) neurons. Thus, TH and DA are markers for both DA and NA neurons. Since mDA neurons and NA neurons from the locus coeruleus send projections to the PFC (Levitt and Moore, 1979), TH or DA staining in the PFC should in principle detect both DA and NA axons. However, double immunohistochemistry for TH and Dopamine beta-hydroxylase (DBH, a specific marker for NA axons) in the prefrontal areas of adult human brain shows that approximately $15 \%$ of $\mathrm{DBH}$-positive axons are also co-labeled with TH. In fetal brains, the overlap is even lower (ca. 5\%) (Gaspar et al., 1989; Verney et al., 1993). These data suggest that, at least in humans, both during development and in the adult brain, TH immunoreactivity in axonal fibers is largely restricted to projections from mDA neurons. Nevertheless, when drawing conclusions from studies using TH or DA as markers for mDA projections in the PFC, it should be kept in mind that NA fibers may also be labeled to a certain extent.

In the adult rodent mPFC, there is a dense input of $\mathrm{TH}$ positive fibers to the deep layers, while innervation of $\mathrm{TH}$ expressing fibers is much sparser in the superficial layers of the mPFC, except for the caudal cingulate cortex, which also has dense TH-positive innervation in layers I-III (Kalsbeek et al., 1988; Naneix et al., 2012).

In the developing rodent brain, $\mathrm{TH}$ immunoreactivity reveals that $\mathrm{mDA}$ neurons in the ventral midbrain of rodents start to extend axonal processes between E11 and E12. In mice, axons initially grow slightly dorsally, but by E13, almost all axons follow a rostral course and by E13.5 form a TH-positive axon tract within the MFB, which is directed toward forebrain targets (Nakamura et al., 2000; Kolk et al., 2009). One day later in development, the TH-positive fiber tract reaches a region ventral to the ganglionic eminences (Kolk et al., 2009). Analysis of DA-positive fiber bundles in rats showed that they reach this region also around E14 (Kalsbeek et al., 1988; Voorn et al., 1988). In mice, while most of the TH-positive axons from the MFB begin to move dorsally to innervate the maturing striatum, a small number of fibers follows a rostrodorsal trajectory towards the frontal cortex. These TH-positive axons follow two paths to reach the mPFC. The larger TH bundle bends just before the olfactory bulb and extends toward the cortical subplate, while the smaller subset of TH axons passes through the striatum to the developing $\mathrm{mPFC}$. The TH-positive fibers arrive in the subplate and marginal zone around E15 and continue to grow for about 2 days without entering the cortical plate, which develops and enlarges in the meantime. At E18.5, the first TH-positive axons are detected in the cortical plate (Figure 2). Tracing experiments with the lipophilic fluorescent dye DiI show that after microinjection of DiI into the mPFC at E16.5 and postnatal day (P)0, the dye is eventually detected in the rostral VTA. Conversely, after DiI microinjection into the rostromedial VTA, DiI-stained, THpositive axons are found in the subplate at E16 and in the cortical plate at E18.5. However, no DiI-stained fibers are found in the marginal zone of the PFC in the latter experiment. Together, these data suggest that one subset of mesoprefrontal projections in mice originates in the rostral medial VTA, while a second subset originates from mDA neurons in another ventral midbrain region (Kolk et al., 2009). In rats, the TH-positive axons within the MFB also arrive in the mPFC in two separate bundles. At E18, one of the axonal bundles is observed above the subplate while the other axonal trail can be detected within the marginal zone. The DA fibers in the future mPFC adopt a coiled structure and start innervating the thickening cortical plate from E20 onwards (Kalsbeek et al., 1988; Kolk et al., 2009; Garcia et al., 2019).

Shortly after birth, DA-positive fibers in rats are primarily located in the developing layer VI of mPFC, orbital cortex, and caudal cingulate cortex (defined as supragenual mPFC in the original study by Kalsbeek and colleagues). At P2, the fiber density in layer VI increases substantially. Between P2 and P4, the DA axons change their morphology from thick, straight fibers to thin fibers with irregularly shaped varicosities. This marks the beginning of postnatal maturation of DA-positive fibers in the $\mathrm{mPFC}$, which continues into early adulthood. By the end of the first postnatal week, the infralimbic subdomain of the mPFC shows already an adult-like pattern of DA innervation, with DA-positive fibers reaching up to the pial surface. In other areas of the mPFC, only a few DA-positive fibers in layer I are detectable at this developmental stage. The density of DA fibers in the deeper layers continues to increase in the second postnatal week. At P20, DA-positive projections reach the upper cortical layers II and I in the prelimbic cortex. At this stage, the DApositive fibers in layer I of the anterior cingulate cortex of mPFC fade away, but the projections in the caudal cingulate cortex are found in layers II and III. The morphological characteristics of DA-positive fibers in the mPFC, with thin axons and multiple varicosities, do not change significantly after P35, but the density of fibers continues to increase until adulthood, with the deeper layers becoming more densely innervated than the upper layers (Kalsbeek et al., 1988). TH immunostaining in rat mPFC shows that the increase in TH-positive fibers is relatively rapid during adolescence, whereas the density of DBH-expressing NA fibers in mPFC remains constant from early adolescence to adulthood (Naneix et al., 2012; Willing et al., 2017) (Figure 2). The delayed 
developmental trajectory of prefrontal TH-positive axons from early adolescence to adulthood is similar in male and female rats, even though pubertal onset is approximately 10 days earlier in female than in male rats. These data indicate that sex or pubertal onset do not affect the maturation profile of mesoprefrontal innervation (Willing et al., 2017).

In addition to the innervation density, the formation of varicosities on DA fibers and thus potential release sites is likely another important indicator of functional maturation of DA fibers. DA immunoreactive varicosities have been found to form appositions with both pyramidal and nonpyramidal somata in the mPFC. This is especially noticeable in layer VI, where the density of DA varicosities is higher and GABA-positive cell bodies are frequently found to be in close contact with DA varicosities (Benes et al., 1993). The number of close appositions formed by GABA-positive cell bodies with DA varicosities shows a steady increase from P5 to P60, while the number of varicosities closely interacting with each GABA-positive neuron increases more rapidly during the postweaning period (P25-P59) to reach young adult levels (P60) (Benes et al., 1996).

In mice, the change in TH/DA fiber density in the mPFC during the juvenile and adolescent periods has not yet been studied in detail. To gain insight into potential mechanisms underlying protracted DA innervation of the mPFC, Reynolds and colleagues used an elegant virus-based approach to axon labeling. In this study, retrogradely transported canine adenovirus (CAV) expressing Cre recombinase was injected into the nucleus accumbens of mice during early adolescence (P21), whereas a virus expressing a fluorescent protein after Cremediated recombination was injected into the VTA. CAV-Cre is taken up by axon terminals in the nucleus accumbens, so that only VTA neurons whose axons have reached the nucleus accumbens around P21 are fluorescently labeled. The authors then showed that fluorescently labeled fibers are present in the $\mathrm{mPFC}$ of adult mice. These results indicate that the late maturation of DA fibers in the MPFC may be due to at least some of the fibers initially innervating the nucleus accumbens and only projecting into the mPFC during later stages of adolescence (Reynolds et al., 2018).

Directing the extending DA axons to their proper targets requires precise coordination of extracellular axon guidance cues, receptor complexes, cell adhesion molecules, neurotrophic and growth factors (Hoops and Flores, 2017; Vosberg et al., 2020). Several guidance cue pathways involved in regulating the axonal pathfinding of mesoprefrontal DA axons have been identified. This includes Ephrins, Slits, Semaphorins, Netrins and their receptors. During early stages of $\mathrm{mDA}$ development, Semaphorin $3 \mathrm{~F}$ acts via its receptor Neuropilin-2 to repel mDA axons away from the midbrain, while it changes its role into a chemoattractant to guide the DA axons towards the cortical plate of the $\mathrm{mPFC}$ at the prenatal stage (Kolk et al., 2009). The extracellular protein Netrin-1 and its receptor, DCC (deleted in colorectal cancer) also play a key role in mesoprefrontal/mesolimbic axon growth and the fine-tuning of their expression levels during adolescence is critical to help DA axons find their final target (Reynolds et al., 2018). We will not discuss these molecular mechanisms further here, as they have been extensively addressed in two recent reviews (Brignani and Pasterkamp, 2017; Hoops and Flores, 2017).

\section{DEVELOPMENT OF THE MESOPREFRONTAL DOPAMINERGIC PROJECTIONS IN PRIMATES}

In the adult primate brain, the densest $\mathrm{TH}$-positive innervation is observed in primary motor cortex rather than in PFC areas (Gaspar et al., 1989; Raghanti et al., 2008). While primary motor cortex (area 4) shows even distribution of TH-positive fibers across all layers in the human brain, the PFC shows a bilaminar distribution with highest innervation density in layer I and V-VI (area 9 and 32) (Gaspar et al., 1989; Raghanti et al., 2008). Such bilaminar innervation was not detected in adult non-human primate PFC (Lewis and Harris, 1991; Rosenberg and Lewis, 1995; Raghanti et al., 2008). On an ultrastructural level, electron microscopy of DA axonal boutons (marked with antibodies against $\mathrm{DA}$ and $\mathrm{TH}$ ) in the $\mathrm{PFC}$ of rhesus monkey shows that they form symmetric synaptic connections with dendritic spines of pyramidal cells (Goldman-Rakic et al., 1989). In addition, DA afferents also contact dendrites of nonpyramidal inhibitory interneurons in rhesus monkey PFC (Smiley and Goldman-Rakic, 1993).

How does this innervation pattern develop? Similar to rodents, primate mesoprefrontal DA fibers undergo a protracted development that may involve reorganization of innervation density until the functionally mature innervation pattern of the adult brain is established (Gaspar et al., 1989; Raghanti et al., 2008). In rhesus monkey, TH-expressing axons are observed in the cortical anlage during the 10th gw (Verney, 1999). In neonatal rhesus monkeys, the TH positive innervation is bilaminar in the PFC (area 9), similar to the pattern in the adult human brain. $\mathrm{TH}$ positive axons in the rhesus monkey PFC are reorganized from birth till adulthood, resulting in the relatively uniform distribution of $\mathrm{TH}$ positive innervation across layers in the adult PFC (Lewis and Harris, 1991; Rosenberg and Lewis, 1995). Accordingly, it is the innervation of intermediated cortical layers (especially layer III) that increases with age and reaches its peak in 2-3-year-old adolescent rhesus monkeys (Rosenberg and Lewis, 1995). Based on the observation that the direct effect of DA on the spontaneous activity of PFC neurons is mostly inhibitory, the increased TH positive innervation in layer III of adolescent PFC might indicate an increase in a DA-mediated inhibitory effect onto the pyramidal neurons in these layers (Rosenberg and Lewis, 1995; Figure 2).

In humans, $\mathrm{TH}$-expressing neurons are detected as early as $6 \mathrm{gw}$ and already extend processes that eventually give rise to the mesencephalic tract. This tract, along with the dorsal tegmental bundle, forms the MFB (Zecevic and Verney, 1995; Verney, 1999). TH-positive fibers enter the telencephalic wall at 7-8 gw but remain below the cortical plate (intermediate and subplate area) for 4 weeks before they enter the cortex (Zecevic and Verney, 1995). At 20-24 gw, DA innervation is observed in the frontal cortex with a higher density of TH positive innervation in the anterior cingulate and motor area compared 
to the rostral prefrontal cortical anlage (Verney et al., 1993). It is interesting that this area-specific distribution and density of TH-expressing fibers at this stage is similar to what has been reported in the adult cortex (Gaspar et al., 1989; Verney et al., 1993; Verney, 1999), suggesting that the DA innervation pattern is in principle established already during fetal development in the human brain and subsequently only increases in density. Eventually, the adult PFC acquires its distinctive bilaminar innervation pattern (Gaspar et al., 1989; Raghanti et al., 2008; Figure 2).

Similar to the timing of differentiation onset of $\mathrm{mDA}$ neurons in rodents and primates, the outgrowth of $\mathrm{TH}$-positive fibers and frontal cortex innervation also seems to occur earlier in humans than in rodents as $11 \mathrm{gw}$ in humans is considered a much earlier gestational timepoint than E18 or E20 in mice and rats, respectively (Clancy et al., 2001; Figure 2 and Supplementary Figure 1).

\section{DOPAMINE RELEASE AND DOPAMINE RECEPTORS IN THE DEVELOPING PREFRONTAL CORTEX}

While the location and density of DA projections gives some indication about when and where mesoprefrontal mDA neurons may modulate PFC function, the functional relevance of these projections can only be fully assessed by insights into actual DA release, DA receptor (DRD) expression, and the response of receiving cells to the DA release. In addition, as discussed previously, the release of neurotransmitters other than DA (most prominently glutamate) is likely to contribute to the functional output of the mesoprefrontal mDA neurons.

\section{Dopamine Release}

Analysis of DA and its metabolites in rat mPFC by high throughput liquid chromatography (HPLC) showed that DA concentrations were significantly lower in juvenile and adolescent rats than in adults. DA concentration rose steadily between the juvenile (P25) and late adolescent stages (P45) and increased particularly sharply between the end of adolescence and adulthood. In parallel, a decrease in DA turnover ratios was observed with increasing age, an effect that could contribute to the overall increase in DA availability in the mPFC (Naneix et al., 2012). Analysis of DA tissue concentrations in rhesus monkey PFC showed that DA levels fluctuated between 2, 5, 8 and 15-18 months old animals and significantly increased in 2-3 years old animals (Goldman-Rakic and Brown, 1982). These data suggest that both in rats and rhesus monkey, the overall DA concentration coincides with the increase in DA fiber innervation of the PFC. However, whether this increase in concentration correlates with active DA release has not been investigated in the developing PFC. The recent development of genetically encoded DA sensors that allow the monitoring of DA release in the behaving animal, offer the opportunity to correlate behavior, PFC function and DA release in real-time in adolescent and adult animals (Labouesse et al., 2020).

\section{Dopamine Receptors and Downstream Signaling}

Once released from the axonal varicosities of DA axons, DA binds to DA receptors (DRDs) of the D1-like or D2-like subfamily of G-protein coupled receptors. DRD1 and DRD5 belong to the D1-like subfamily, while DRD2, DRD3, and DRD4 are subtypes of the D2-like subfamily. Unlike Drd1 and Drd5, the D2-like subfamily receptor genes contain introns that allow differential splicing of the transcripts, generating additional isoforms. Drd2 comes in two alternatively spliced variants, Drd2s (short form) and Drd2l (long form), and isoforms of Drd3 and Drd4 have also been identified (Missale et al., 1998). D1-like receptors signal by coupling to $G$ proteins $G_{a s}$ and $\mathrm{G}_{\mathrm{a} \text { olf }}$, which stimulate adenylyl cyclase and lead to activation of protein kinase A (PKA). D2-like receptors stimulate $G_{a i}$ and $\mathrm{G}_{\mathrm{a} o}$ proteins, blocking adenylyl cyclase and consequently inhibiting PKA activity (Missale et al., 1998; Tritsch and Sabatini, 2012). Furthermore, DRDs can activate a signaling cascade by interacting with $ß$-arrestin (Beaulieu et al., 2005) or induce phospholipase C-mediated increase of intracellular calcium levels (Lee et al., 2004), although the signal transduction pathway of this modulation remains to be resolved (Chun et al., 2013). The striatum and the nucleus accumbens receive dense projections from mDA neurons and have high expression levels of DRDs. In the PFC, the expression levels of the DRDs are considerably lower, correlating with relatively sparse innervation by DA fibers.

\section{Dopamine Receptor Expression in Rodent Prefrontal Cortex}

The distribution and expression of DRDs and their transcripts in rodent PFC have been studied using multiple histological methods, real-time quantitative PCR and in recent years, genetic tools and single-cell transcriptome analysis (Table 1). Early studies include autoradiographic experiments employing radiolabeled agonist or antagonist of DRDs (Boyson et al., 1986; Noisin and Thomas, 1988), immunohistochemical and immunoblotting approach targeting the receptor protein (Levey et al., 1993; Sesack et al., 1994) and in-situ hybridization technique detecting Drd transcripts (Gaspar et al., 1995). Some of the radioligands used in binding assays were later found to lack selectivity for specific subtypes of DRD (Landwehrmeyer et al., 1993) and similar doubts have been expressed for commercially available antibodies for the receptors (Bodei et al., 2009). RNA in situ hybridization methods have characterized the distribution of certain Drd mRNAs within the subregions of the PFC (Santana and Artigas, 2017) and RT-qPCR approaches were used to quantify the relative gene expression of the Drd subtypes in the PFC (Araki et al., 2007). Whether the transcript levels reliably correspond to the expression levels of DRD protein is not known.

Taking into account these methodological limitations, studies on DRD proteins and their transcripts indicate that of the five DRD subtypes, DRD1 and its mRNA are most highly expressed in the adult rodent PFC, followed by DRD2/Drd2. In comparison, DRD3, 4 and 5 show limited expression (Tarazi and Baldessarini, 
TABLE 1 | Laminar distribution of Drds/DRDs in the PFC of rodent, rhesus monkey and human.

\begin{tabular}{|c|c|c|c|c|c|c|c|c|c|c|c|c|c|c|c|c|}
\hline & \multirow{2}{*}{$\begin{array}{l}\text { Receptor/ } \\
\text { Gene }\end{array}$} & \multicolumn{6}{|c|}{ Rodent } & \multicolumn{9}{|c|}{ Human / Non-human Primate } \\
\hline & & L2/3 & L5 & L6 & Species & Method & References & L1 & L2 & L3 & L4 & L5 & L6 & Species & Method & References \\
\hline \multirow{5}{*}{$\begin{array}{l}\text { D1-like } \\
\text { Family }\end{array}$} & $\begin{array}{l}\text { DRD1/ } \\
\text { Drd1 }\end{array}$ & ++ & ++ & +++ & Rats & In situ & $\begin{array}{l}\text { Santana and } \\
\text { Artigas, } 2017\end{array}$ & $(+)$ & +++ & ++ & ++ & +++ & +++ & Humans & In situ & $\begin{array}{l}\text { Weickert } \\
\text { et al., } 2007\end{array}$ \\
\hline & & ++ & +++ & +++ & Rats & Receptor binding & $\begin{array}{l}\text { Vincent et al., } \\
1993\end{array}$ & & & & & & & & & \\
\hline & & ++ & ++ & +++ & Mice & Genetic labeling & Wei et al., 2018 & +++ & +++ & +++ & ++ & +++ & +++ & $\begin{array}{l}\text { Rhesus } \\
\text { Monkeys }\end{array}$ & $\begin{array}{c}\text { Receptor } \\
\text { Autoradiography }\end{array}$ & $\begin{array}{l}\text { Lidow and } \\
\text { Rakic, } 1992\end{array}$ \\
\hline & $\begin{array}{l}\text { DRD5 / } \\
\text { Drd5 }\end{array}$ & ++ & ++ & ++ & Mice & Immunohistochemistry & $\begin{array}{l}\text { Lidow et al., } \\
2003\end{array}$ & & & & & & & & & \\
\hline & & +++ & ++ & ++ & Rats & Immunohistochemistry & $\begin{array}{l}\text { Ciliax et al., } \\
2000\end{array}$ & & & & & & & & & \\
\hline \multirow[t]{6}{*}{$\begin{array}{l}\text { D2-like } \\
\text { Family }\end{array}$} & $\begin{array}{l}\text { DRD2 / } \\
\text { Drd2 }\end{array}$ & + & +++ & ++ & Rats & In situ & $\begin{array}{l}\text { Santana and } \\
\text { Artigas, } 2017\end{array}$ & $(+)$ & ++ & + & + & +++ & +++ & Humans & In situ & $\begin{array}{l}\text { Weickert } \\
\text { et al., } 2007\end{array}$ \\
\hline & & ++ & +++ & +++ & Rats & Receptor binding & $\begin{array}{l}\text { Vincent et al., } \\
1993\end{array}$ & & & & & & & & & \\
\hline & & + & +++ & ++ & Rats & Genetic labeling & Yu et al., 2019 & ++ & ++ & ++ & ++ & +++ & ++ & $\begin{array}{l}\text { Rhesus } \\
\text { Monkeys }\end{array}$ & $\begin{array}{c}\text { Receptor } \\
\text { Autoradiography }\end{array}$ & $\begin{array}{l}\text { Lidow and } \\
\text { Rakic, } 1992\end{array}$ \\
\hline & & +++ & ++ & ++ & Mice & Genetic labeling & Wei et al., 2018 & & & & & & & & & \\
\hline & $\begin{array}{l}\text { DRD3 / } \\
\text { Drd3 }\end{array}$ & $?$ & $?$ & ++ & Mice & Genetic labeling & $\begin{array}{l}\text { Li and } \\
\text { Kuzhikandathil, } \\
2012\end{array}$ & & & & & & & & & \\
\hline & $\begin{array}{l}\text { DRD4 / } \\
\text { Drd4 }\end{array}$ & $?$ & ++ & ++ & Mice & Genetic labeling & $\begin{array}{l}\text { Noaín et al., } \\
2006\end{array}$ & $(+)$ & ++ & + & ++ & +++ & +++ & Humans & In situ & $\begin{array}{l}\text { Weickert } \\
\text { et al., } 2007\end{array}$ \\
\hline
\end{tabular}

L, cortical layer; +++ highest expression; ++ intermediate expression; + low expression; (+) absent/very low expression. 
2000; Lidow et al., 2003; Araki et al., 2007; Rajput et al., 2009; Santana et al., 2009). DRD1 and DRD2 are expressed in both pyramidal neurons and interneurons of rodent PFC but are rarely colocalized (Santana et al., 2009; Zhang et al., 2010). RNA in situ hybridization studies in adult rats show that cells expressing Drd1 mRNA are most prominent in layer VI, extending into layer $\mathrm{V}$, with an additional thin band of positive cells in layer II. Drd2-expressing cells are mainly localized in layer V and VI, with few positive cells in layer II and III (Gaspar et al., 1995; Santana and Artigas, 2017). This laminar distribution pattern of DRD1 and DRD2 in rat mPFC was also observed in an earlier receptor binding study using fluorescently coupled receptor antagonists (Vincent et al., 1993). More recently, genetic labeling has emerged as an additional tool to monitor Drd1- and Drd2expressing neurons in rodents. Genetic labeling studies involve transgenic mice that accommodate a BAC (bacterial artificial chromosome) construct containing $\operatorname{Drd} 1$ or $\operatorname{Drd} 2$ regulatory regions directing expression of Cre recombinase (Drd1-Cre or Drd2-Cre mice) (Gong et al., 2007). These Cre mice are crossed with reporter mice that express fluorescent proteins upon Cremediated recombination (such as Ai14 or Ai6 mice) allowing the identification of cells that express Drd1 or Drd2 (Madisen et al., 2010; Wei et al., 2018). In rats, Drd2-Cre knock-in animals have been generated and crossed with a fluorescent rat reporter line (Ai9) (Madisen et al., 2010; Yu et al., 2019). An important aspect to keep in mind with these Cre reporter systems is that recombination of the reporter allele is permanent, meaning that if the $\operatorname{Drd} 1$ or $\operatorname{Drd} 2$ promoter is transiently active in certain cell populations during embryonic or postnatal development, these cells will be recombined and continue to express the fluorescent protein in the adult brain even when these neuronal populations may no longer express $\operatorname{Drd} 1$ or $\operatorname{Drd} 2$ in the adult. Furthermore, in this system, the expression level of the fluorescent protein does not correspond to the level of endogenous gene or protein expression. Despite these caveats, in Drd2-Cre, Ai9 reporter rats, the distribution of recombined cells (expressing fluorescent reporter protein) is largely in agreement with previous findings on Drd2 expression in the mPFC (Santana and Artigas, 2017). Analysis of recombined cells in the anterior cingulate cortex show them mostly to be putative pyramidal neurons of upper and deep layers. Only a small number of inhibitory interneurons exhibit fluorescent labeling in this region (Yu et al., 2019). Similarly, in Drd1-Cre, Ai6 or Drd1-Cre, Ai14 reporter mice, fluorescently labeled cells show a laminar distribution comparable to what has been reported for Drd1 transcript expression in mPFC, with a higher overall density of Drd1 expression in deep layers. In Drd2Cre Ai6/Ai14 mice, however, distribution of fluorescently labeled cells in mPFC is strikingly distinct from the one reported in Drd2-Cre, Ai9 reporter rats or the expression patterns observed in RNA in situ hybridization studies, showing high expression of Drd2 in superficial layers rather than in deep layers (Wei et al., 2018). Whether this is due to the different approaches used to generate the Cre-lines (BAC transgenic mice versus knock-in rats) or reflects a transient expression of Drd2 in superficial layers of the $\mathrm{mPFC}$ during development in the mouse is unclear (Beil et al., 2012; Yu et al., 2019). BAC transgenic mice expressing enhanced green fluorescent protein (EGFP) under the transcriptional regulation of Drd3 (Drd3-Egfp mice) or Drd4 (Drd4-Egfp mice) locus have also been used to study the expression of Drd3 and Drd4 in different regions of the brain (Gong et al., 2003). In the Drd3-Egfp mouse model, the fluorescent cells in the caudal cingulate cortex are mainly located in layer VI (Li and Kuzhikandathil, 2012). Analysis of Drd4-Egfp mice showed strongly labeled EGFP-expressing neurons in layer V and VI of prelimbic and cingulate cortices (Noaín et al., 2006). DRD5 immunoreactivity has been detected in layer II to layer VI of prelimbic and cingulate cortices, with more labeled cells in layer II and III. In mice, DRD5 is more uniformly distributed across the cortical layers of the mPFC (Ciliax et al., 2000; Lidow et al., 2003; Table 1).

The developmental time course of DRD expression in rodent PFC is not well characterized and appears to vary considerably between rats and mice. RT-qPCR analysis in the murine cingulate cortex (both at rostral and caudal levels) at P0, P21, and P60 reveals that other than Drd4, which has the highest expression at birth followed by a rapid postnatal decrease in expression, transcript levels of the Drd subtypes do not show any significant developmental change between P0 and P60 (Araki et al., 2007). In the frontal cortex of rats, in situ hybridization signals for Drd1 or Drd2 transcripts have been detected around E14 or E18, respectively (Schambra et al., 1994). According to the same study, expression levels for both Drd1 and Drd2 appear to reach maximal levels between P14 and P30, although the change in signal intensity has not been quantified. Another study, however, shows that Drd1, Drd5, Drd4, Drd2l (but not Drd2s) expression in the mPFC of rats reaches peak expression only at P45 and then decreases between P45 and P70 (Naneix et al., 2012). At the protein level, there is a marked decline of DRD1 and DRD2 density in PFC of rats between adolescence (P40) and adulthood (P120) (Andersen et al., 2000). An earlier study using quantitative autoradiography in rats has described a similar pattern for DRD1 in MPFC, but with peak receptor binding density at P14 and P21, and a decrease in binding between P21-P42 (Leslie et al., 1991). A certain population of $\mathrm{mPFC}$ pyramidal neurons projecting to the nucleus accumbens also shows differential expression of DRD1 across postnatal development. In retrogradely traced prelimbic pyramidal neurons projecting to the nucleus accumbens core, the number of DRD1 immunoreactive cells was significantly higher in adolescents (P44) than in juveniles (P27) or adults (P105) (Brenhouse et al., 2008). Tarazi and Baldessarini, however, report a different temporal expression pattern in frontal cortex of rats. In their investigation, binding of radioligands to DRD1, DRD2 and DRD4 receptors gradually rises from P7 to maximal levels at P60 (Tarazi and Baldessarini, 2000). Overall, the data from various published studies do not deliver a conclusive picture on the time course and distribution of DRD/Drd expression in the developing mPFC (Table 2).

An additional potent tool to investigate the distribution of Drd transcripts is single-cell mRNA sequencing (scRNA seq). DropViz is an extensive collection of scRNA seq data, assembled from analysis of RNA expression of thousands of individual cells across different regions of mouse brain (P60P70) (Macosko et al., 2015; Saunders et al., 2018). Based on 
TABLE 2 | Relative changes in expression of Drds/DRDs in PFC throughout postnatal development.

\begin{tabular}{|c|c|c|c|c|c|c|c|c|c|c|c|c|c|c|c|c|c|c|c|}
\hline & \multirow{2}{*}{$\begin{array}{l}\text { Receptor/ } \\
\text { Gene }\end{array}$} & \multicolumn{8}{|c|}{ Rodent } & \multicolumn{10}{|c|}{ Human / Non-human Primate } \\
\hline & & ow & $1 W$ & $3 w$ & $6 W$ & $9 \mathrm{~W}$ & Species & Method & References & s1 & s2 & S3 & S4 & S5 & s6 & s7 & Species & Method & References \\
\hline \multirow[t]{6}{*}{$\begin{array}{l}\text { D1 - like } \\
\text { Family }\end{array}$} & $\begin{array}{l}\text { DRD1 / } \\
\text { Drd1 }\end{array}$ & + & & $\leftrightarrow$ & & $\leftrightarrow$ & Rats & RT-qPCR & $\begin{array}{l}\text { Araki et al., } \\
2007\end{array}$ & + & $\downarrow$ & & & $\uparrow$ & $\leftrightarrow$ & $\downarrow$ & Humans & In situ & $\begin{array}{l}\text { Weickert } \\
\text { et al., } 2007\end{array}$ \\
\hline & & & & + & $\uparrow$ & $\downarrow^{*}$ & Rats & In situ & $\begin{array}{l}\text { Naneix et al., } \\
2012\end{array}$ & + & $\uparrow$ & $\uparrow$ & $\uparrow$ & $\leftrightarrow$ & $\downarrow$ & $\downarrow$ & Humans & $\begin{array}{l}\text { RT-qPCR + } \\
\text { Microarray }\end{array}$ & $\begin{array}{l}\text { Rothmond } \\
\text { et al., } 2012\end{array}$ \\
\hline & & & + & $\uparrow^{*}$ & $\uparrow$ & $\uparrow$ & Rats & $\begin{array}{c}\text { Receptor } \\
\text { Autoradiography }\end{array}$ & $\begin{array}{l}\text { Tarazi and } \\
\text { Baldessarini, } \\
2000\end{array}$ & + & $\uparrow$ & $\uparrow$ & $\leftrightarrow$ & $\uparrow$ & $\uparrow^{*}$ & $\leftrightarrow$ & Humans & Western Blot & $\begin{array}{l}\text { Rothmond } \\
\text { et al., } 2012\end{array}$ \\
\hline & & & + & $\uparrow$ & $\downarrow$ & & Rats & $\begin{array}{c}\text { Receptor } \\
\text { Autoradiography }\end{array}$ & $\begin{array}{l}\text { Leslie et al., } \\
1991\end{array}$ & + & $\leftrightarrow$ & $\uparrow^{*}$ & $\downarrow$ & $\downarrow$ & $\leftrightarrow$ & $\leftrightarrow$ & $\begin{array}{l}\text { Rhesus } \\
\text { Monkeys }\end{array}$ & $\begin{array}{c}\text { Receptor } \\
\text { Autoradiography }\end{array}$ & $\begin{array}{l}\text { Lidow and } \\
\text { Rakic, } 1992\end{array}$ \\
\hline & $\begin{array}{l}\text { DRD5 / } \\
\text { Drd5 }\end{array}$ & + & & $\leftrightarrow$ & & $\leftrightarrow$ & Rats & RT-qPCR & $\begin{array}{l}\text { Araki et al., } \\
2007\end{array}$ & + & $\leftrightarrow$ & $\leftrightarrow$ & $\leftrightarrow$ & $\leftrightarrow$ & $\leftrightarrow$ & $\leftrightarrow$ & Humans & $\begin{array}{l}\text { RT-qPCR + } \\
\text { Microarray }\end{array}$ & $\begin{array}{l}\text { Rothmond } \\
\text { et al., } 2012\end{array}$ \\
\hline & & & & + & $\uparrow$ & $\downarrow^{*}$ & Rats & RT-qPCR & $\begin{array}{l}\text { Naneix et al., } \\
2012\end{array}$ & & & & & & & & & & \\
\hline \multirow[t]{8}{*}{$\begin{array}{l}\text { D2 - like } \\
\text { Family }\end{array}$} & $\begin{array}{l}\text { DRD2 / } \\
\text { Drd2 }\end{array}$ & + & & $\leftrightarrow$ & & $\leftrightarrow$ & Rats & RT-qPCR & $\begin{array}{l}\text { Araki et al., } \\
2007\end{array}$ & + & $\downarrow^{*}$ & & & $\uparrow$ & $\downarrow$ & $\uparrow$ & Humans & In situ & $\begin{array}{l}\text { Weickert } \\
\text { et al., } 2007\end{array}$ \\
\hline & Drd2l & & & + & $\uparrow$ & $\downarrow^{*}$ & Rats & RT-qPCR & $\begin{array}{l}\text { Naneix et al., } \\
2012\end{array}$ & + & $\downarrow$ & $\uparrow$ & $\downarrow$ & $\downarrow$ & $\leftrightarrow$ & $\leftrightarrow$ & Humans & RT-qPCR & $\begin{array}{l}\text { Rothmond } \\
\text { et al., } 2012\end{array}$ \\
\hline & $\operatorname{Drd} 2 \mathrm{~s}$ & & & + & $\leftrightarrow$ & $\leftrightarrow$ & Rats & RT-qPCR & $\begin{array}{l}\text { Naneix et al., } \\
2012\end{array}$ & + & $\downarrow$ & $\leftrightarrow$ & $\downarrow^{*}$ & $\leftrightarrow$ & $\leftrightarrow$ & $\leftrightarrow$ & Humans & RT-qPCR & $\begin{array}{l}\text { Rothmond } \\
\text { et al., } 2012\end{array}$ \\
\hline & & & + & $\uparrow^{*}$ & $\uparrow$ & $\uparrow$ & Rats & $\begin{array}{c}\text { Receptor } \\
\text { Autoradiography }\end{array}$ & $\begin{array}{l}\text { Tarazi and } \\
\text { Baldessarini, } \\
2000\end{array}$ & + & $\leftrightarrow$ & $\uparrow^{\star}$ & $\downarrow$ & $\leftrightarrow$ & $\leftrightarrow$ & $\leftrightarrow$ & $\begin{array}{l}\text { Rhesus } \\
\text { Monkeys }\end{array}$ & $\begin{array}{c}\text { Receptor } \\
\text { Autoradiography }\end{array}$ & $\begin{array}{l}\text { Lidow and } \\
\text { Rakic, } 1992\end{array}$ \\
\hline & $\begin{array}{l}\text { DRD3 / } \\
\text { Drd3 }\end{array}$ & + & & $\leftrightarrow$ & & $\leftrightarrow$ & Rats & RT-qPCR & $\begin{array}{l}\text { Araki et al., } \\
2007\end{array}$ & & & & & & & & & & \\
\hline & $\begin{array}{l}\text { DRD4 / } \\
\text { Drd4 }\end{array}$ & + & & $\downarrow^{*}$ & & $\leftrightarrow$ & Rats & RT-qPCR & $\begin{array}{l}\text { Araki et al., } \\
2007\end{array}$ & + & $\leftrightarrow$ & & & $\leftrightarrow$ & $\leftrightarrow$ & $\leftrightarrow$ & Humans & In situ & $\begin{array}{l}\text { Weickert } \\
\text { et al., } 2007\end{array}$ \\
\hline & & & & + & $\uparrow$ & $\downarrow^{*}$ & Rats & RT-qPCR & $\begin{array}{l}\text { Naneix et al., } \\
2012\end{array}$ & + & $\leftrightarrow$ & $\leftrightarrow$ & $\leftrightarrow$ & $\leftrightarrow$ & $\leftrightarrow$ & $\leftrightarrow$ & Humans & RT-qPCR & $\begin{array}{l}\text { Rothmond } \\
\text { et al., } 2012\end{array}$ \\
\hline & & & + & $\uparrow^{*}$ & $\uparrow$ & $\uparrow$ & Rats & $\begin{array}{c}\text { Receptor } \\
\text { Autoradiography }\end{array}$ & $\begin{array}{l}\text { Tarazi and } \\
\text { Baldessarini, } \\
2000\end{array}$ & & & & & & & & & & \\
\hline
\end{tabular}

+ first postnatal stage analyzed \& expression detected. $\uparrow$ increase; $\downarrow$ decrease; $\leftrightarrow$ no change in expression compared to previous timepoint; * indicates increase or decrease in expression compared to previous timepoint that were statistically significant; empty cells: no data available. W: Week S: Stage; S1: neonate in humans, 0 month in rhesus monkeys; S2: infant in humans, 1 month in rhesus monkeys; S3: toddler in humans, 2 months in rhesus monkeys; S4: school age in humans, 8 months in rhesus monkeys; S5: adolescent in humans, 12 months in rhesus monkeys; S6: young adult in humans, 36 months in rhesus monkeys;

s7: adult in humans, 60 months in rhesus monkeys. 
gene expression profiles in the frontal cortex (including the mPFC, orbital cortices, frontal association cortex, anterior parts of primary and secondary motor cortices, insular cortex and somatosensory cortex), Drd1 and Drd5 expression is highest in deep layer pyramidal neurons and Drd4 is mostly expressed in pyramidal cells of layer II/III. Drd2 transcript levels are notably low and are predominantly found in interneurons rather than in projection neurons. Additionally, a rather remarkable observation is that the highest level of Drd1 and Drd2 expression is found in microglia. Drd3 expression is not included in this transcriptional analysis of the frontal cortex, possibly because of low expression levels. The transcriptional dynamics of the Drds in the frontal cortex during development has not yet been investigated. However, dynamic regulation of Drd1 has been demonstrated in the context of mouse models of drug abuse. Bhattacherjee and colleagues have shown that chronic cocaine addiction induces cell type-specific transcriptional changes in the murine mPFC. The effect of cocaine addiction on gene expression changes was particularly striking during the withdrawal period, with excitatory neurons in the deeper layers being more affected. While the most significantly affected excitatory clusters expressed Drd1, the analysis also detected Drd1 expressing excitatory clusters that did not respond robustly to cocaine. Although the functional role of each subtype remains to be investigated, this suggests that certain Drd1-expressing neuronal subtypes in the PFC may be more involved in the process of cocaine addiction than others (Bhattacherjee et al., 2019). Further analysis on dataset of cocaine-addicted mice revealed that Drd1 and Drd2 genes are both upregulated in cocaine addiction and are almost solely expressed in excitatory neurons, with $\operatorname{Drd1}$ also being found at lower levels in inhibitory neurons, oligodendrocyte and endothelial cells in the mPFC (Bhattacherjee et al., 2019; Navandar et al., 2021).

In addition to DRD expression patterns, maturation of receptor function could also contribute to changing impact of the mesoprefrontal system over time. Investigations into DRD function have shown that DRD1-mediated modulation of NMDA receptor transmission prompt recurrent depolarizing plateaus in pyramidal neurons of mPFC slices, an effect that develops only after P45 (Tseng and O'Donnell, 2005). Furthermore, DRD2-mediated increase in excitability of fastspiking interneurons in PFC slices appears only after P50 (Tseng and O'Donnell, 2007). Thus, while the changes in postnatal expression levels of $\mathrm{DRD} / \mathrm{Drd}$ are still unclear, there is indeed a change in activity of DRDs in the postpubertal stage, hinting towards the role of DA in the remodeling of PFC microcircuits during the transition from adolescence to adulthood.

Another gap in our understanding of DRD receptor expression and function in the developing and adult $\mathrm{MPFC}$ is that we know little about the subcellular localization of receptors in DRD-expressing neurons. Because existing antibodies against DRDs have limited utility for detecting DRDs in brain tissue (Bodei et al., 2009), alternative approaches should be considered for investigating this question. Vincent and colleagues analyzed cellular localization of D1- and D2-like family of receptors in the $\mathrm{mPFC}$ using receptor antagonists coupled to fluoroprobes and observed that around $25 \%$ of all fluoroprobe-labeled cells displayed both D1 and D2-like subfamily receptor binding fluorescence along the outer edge of the soma. Further analysis on cell size distribution suggested that the cells in which colocalization could be detected were non-pyramidal (Vincent et al., 1995). A recent promising technique to examine subcellular localization of DRDs may be the application of CRISPR/Cas9 based genome editing tools to introduce fluorescent tags to endogenous receptor proteins. A recent study used a modified CRISPR/Cas9 knock-in strategy with two guide RNAs to knockin a fluorescent protein to $\alpha$-amino-3-hydroxy-5-methyl-4isoxazolepropionic acid (AMPA) and N-methyl D-aspartic acid (NMDA) receptor subunits in primary mouse cortical cultures (Fang et al., 2021). The application of these epitope tags in vivo is also possible. Using the so-called ORANGE (Open Resource for the Application of Neuronal Genome Editing) toolbox, adenoassociated virus plasmids containing fluorescent tag knock-in constructs for PSD95 and AMPA receptor subunit (GLUA1) were injected into the hippocampus of Cas9-P2A-GFP transgenic mice resulting in robust labeling of both proteins (Willems et al., 2020). Applying these methods for the fluorescent tagging of DRDs has the potential to aid in determining the subcellular localization of DRDs in fixed tissue as well as monitoring dynamics of receptor localization in dissociated cell cultures in vitro or in acute slices.

The distribution of DRDs in the rodent mPFC correlates largely with the innervation pattern of DA fibers, suggesting that DRD expression might be influenced by DA release in the mPFC. In this context, DA might play a role during the phase when projections are established (as in a critical developmental period) and/or influence DRD expression levels in the adult brain. Indeed, there is evidence from the striatum that ablating DA innervation during early postnatal development (using 6OHDA-mediated lesion of the nigrostriatal and mesolimbic pathway at neonatal stages) results in reduced binding of radioligand to DRD1 in the caudate putamen and nucleus accumbens of the adult (P90) rat. Radioligand binding to DRD2 is not affected (Thomas et al., 1998). In the adult brain, the loss of striatal DA input in Parkinson's disease patients or in animal models of the disease leads to compensatory upregulation of DRDs, while drug-induced DA increase in the nucleus accumbens leads to reduced expression of DRDs to adjust for elevated DA in the system (Hisahara and Shimohama, 2011; Volkow and Morales, 2015). In the mPFC, the influence of DA on DRD expression has not been studied in detail. One study has examined the effect of depletion of DA projections in the postnatal rat by intracisternal injection of 6-OHDA 5 days after birth and found that DRD1 receptor binding remains unaltered (Leslie et al., 1991). Mouse models interfering with the development of mesoprefrontal projections, such as the Dcc and Netrin-1 haploinsufficient mice that elevate DA transmission in the mPFC (Vosberg et al., 2020) or mouse models that lack mesoprefrontal innervation (Kabanova et al., 2015) may offer a suitable approach to determine the role of DA innervation in the developmental trajectory of DRD expression in the $\mathrm{mPFC}$. 


\section{Dopamine Receptor Expression in Primate Prefrontal Cortex}

In the adult PFC of rhesus monkeys, autoradiographic receptor binding assays showed that DRD1 is most densely present in layers I, II, IIIa, V, and VI, while DRD2 shows the highest expression density in layer $\mathrm{V}$ of adult PFC (Lidow and Rakic, 1992) (Table 1). Immunohistochemistry for DRD1 and DRD5 in rhesus monkey PFC (area 9) demonstrated that these receptors widely colocalize on spines of pyramidal neurons and axon terminals (Bordelon-Glausier et al., 2008). In the adult human PFC, DRD1, DRD2 and DRD4 are highly expressed in deeper layers (layer V and VI) and layer II (Weickert et al., 2007; Table 1). These studies did not report on the expression of DRD3.

DRDs appear to be dynamically expressed in the developing PFC in primates. In the adult rhesus monkey PFC (5-6 years old), DRD1 and DRD2 density (examined by autoradiographic receptor binding assays) was found to be significantly lower compared to 2 months of age (Lidow and Rakic, 1992). Another study, using $\left[{ }^{11} \mathrm{C}\right]$ FLB 457 (high-affinity radioligand for $\mathrm{DRD} 2 / 3$ ) in positron emission tomography (PET) on human subjects (age range 19-74 years), detected a significant decline in DRD2/3 expression with age in the frontal cortex area (Kaasinen et al., 2000). An immunohistochemistry study was not performed for these receptors. At the transcriptional level, a cohort study of human post-mortem PFC tissue revealed that DRD1 mRNA is expressed at neonatal stages. Expression levels decline within the first year of life, are highest during adolescence and young adults, and gradually decline again in adult and aged cohorts (Weickert et al., 2007). However, in a similar cohort study of the human dorsolateral PFC, DRD1 mRNA expression was reported to increase steadily until adolescence but to decrease slightly thereafter. Western blot analysis of DRD1 expression indicated that protein levels also increase gradually with age, but the highest expression was found in the young adult and adult groups (Rothmond et al., 2012). Moreover, a similar layerspecific pattern was observed across all studied ages: DRD1 transcript levels were not detected in layer I of the human dorsolateral PFC, were present at an intermediate level in layers III and IV and highest expression was found in layers II, V, and VI (Weickert et al., 2007). Unlike DRD1, DRD2 expression levels peak at neonatal age, followed by a significant decrease in infants. At all later developmental time points examined, expression levels remain below neonatal levels. Similarly, mRNA levels of the short (DRD2S) and long (DRD2L) DRD2 isoform are highest at the neonatal stage and decrease with age in the dorsolateral PFC. A layer-specific pattern was observed also for $D R D 2$ with highest expressions in layers II, V, and VI. DRD1 and DRD2 mRNA was found in both pyramidal and non-pyramidal neurons in adult brain (Weickert et al., 2007). DRD4 mRNA expression was detected in presumed non-pyramidal neurons and glia but was barely present in pyramidal cells (Weickert et al., 2007). Generally, DRD4 did not show any age-specific changes in expression and highest signal intensity was detected in layer $\mathrm{V}$ (Weickert et al., 2007; Rothmond et al., 2012). DRD5 expression levels did not show any significant differences between age groups (Rothmond et al., 2012). To the best of our knowledge, the distribution of $D R D 3$ expression in the developing primate PFC has not yet been reported (Table 2).

Similar to what we have highlighted above for the investigation of Drd expression in the rodent brain, high-throughput techniques for transcriptome analysis, such as scRNAseq, give now the opportunity to explore the cell-type specific expression of DRD transcripts in the developing and adult human PFC in further detail (Allen Institute for Brain Science, 2010; Fan et al., 2018, 2020; Zhong et al., 2018; Polioudakis et al., 2019; Tanaka et al., 2020; Maynard et al., 2021). This will be instrumental in defining temporal dynamics and cell type-specific responsiveness to DA.

Finally, neither DA release nor receptor expression may offer a full reflection of how DA impacts on cortical neurons in the PFC. As discussed above, DRDs act on DA-receiving cells by modulating PKA activity. Thus, monitoring PKA activity may offer additional insight into the effects of DA on cortical neuronal function. A recent study used a PKA activity sensor to monitor the effect of DA release on Drd1- versus Drd2-expressing medium spiny neurons in the nucleus accumbens during learning in realtime (Lee et al., 2021). However, given that DA innervation and release is much sparser in the $\mathrm{mPFC}$ than in the nucleus accumbens and other modulatory neurotransmitters released in the mPFC (e.g., NA, Serotonin) act also via G-protein coupled receptors and modulation of PKA activity, further studies would be needed to determine whether a similar approach could be applied in the PFC.

In summary, a better understanding of the developmental time course of DA release; the laminar distribution, neuronal subtype expression, and subcellular localization of DRD receptors as well as downstream signaling events would greatly contribute to our knowledge of the functional role of DA in the developing and adult PFC.

\section{THE DEVELOPING MESOPREFRONTAL SYSTEM IN NEUROPSYCHIATRIC DISEASES}

As discussed above, the PFC is the region of the brain that is particularly important for executive functions and the control of goal-directed and self-regulatory behaviors. Dysregulation of local micronetworks in the PFC has been associated with impaired social, affective, and cognitive functions typically seen in neurodevelopmental disorders such as schizophrenia, autism spectrum disorder and attention deficit/hyperactivity disorder as well as in depression and substance abuse disorders. An open question is to what extent deficits in the mesoprefrontal DA system, and thus DA-influenced neuromodulation of local PFC networks, contribute to the pathophysiology of these neuropsychiatric disorders. In particular, it is unclear whether these changes occur secondary to alterations in the PFC (and other cortical areas) or can also be attributed to developmental deficits in the mesoprefrontal DA system. Many of the mutations associated with schizophrenia or autism spectrum disorder are found in genes encoding synaptic proteins. While loss of function of these genes has been shown to lead to deficits in 
synaptic transmission in cortical regions and particularly in the PFC, it is not known whether this also directly affects the function of mesoprefrontal DA neurons (Yan and Rein, 2021). Another point that should be considered in this context, is that mesoprefrontal DA neurons (at least in rodents) can co-release glutamate (Kabanova et al., 2015; Mingote et al., 2015; PérezLópez et al., 2018; Zhong et al., 2020). Thus, any developmental deficits or alterations in the mesoprefrontal system could have consequences for both DA and glutamate release in the PFC. In the following, we will focus on the possible dysfunction of the mesoprefrontal system in three neuropsychiatric diseases with a clear developmental etiology: schizophrenia, autism spectrum disorder, and attention deficit/hyperactivity disorder. In the context of these diseases, we will briefly discuss a few studies that have examined potential alterations in the developing DA system.

\section{Schizophrenia}

Schizophrenia is a neuropsychiatric disorder with severe symptoms that usually become manifest in full during adolescence or early adulthood. These include the socalled positive symptoms (psychosis), negative symptoms (deficits in emotional responses and thought processes), and cognitive dysfunction (e.g., deficits in working memory, longterm memory, semantic processing, learning) (Marder and Cannon, 2019). According to the so-called DA hypothesis of schizophrenia, alterations in DA signaling are a major factor in these disease symptoms: DA hyperactivity in the striatum promotes psychosis, while DA hypoactivity in other brain areas, including the PFC, contributes to the negative symptoms and cognitive dysfunction. There is ample evidence from human studies to support this hypothesis. To name a few: (1) DA agonists and stimulants such as cocaine or amphetamine can induce psychosis in healthy individuals and exacerbate psychosis in patients with schizophrenia; (2) antipsychotic drugs act on the DA system via DRD2 receptors (e.g., haloperidol); (3) postmortem studies have demonstrated increased levels of DRDs, DA, and DA metabolites in the striatum of patients with schizophrenia; (4) imaging studies in patients with schizophrenia show that stimulant-induced presynaptic DA release is decreased in most brain regions, except for the striatum, where it is increased. For further details, we refer the interested reader to a collection of reviews on the DA hypothesis of schizophrenia (Biol Psychiat, 2017).

With respect to the mesoprefrontal DA system, its hypoactivity is most likely associated with the cognitive dysfunctions in schizophrenia. The cause of the overall DA imbalance may be caused by deficits in local cortical or hippocampal networks that in turn lead to changes in the inputs to the VTA from these regions and ultimately to DA hypoactivity in VTA targets. Alternatively, or in addition, defects in the regulation of DA release in target regions (including the PFC) or in the developmental of the mesoprefrontal system could contribute to the DA hypoactivity (Rice et al., 2016; AbiDargham, 2017; Chuhma et al., 2017; Grace, 2017; Walker et al., 2017; Sonnenschein et al., 2020; Braun et al., 2021). Whether the development of the mesoprefrontal DA system (or other parts of the DA system) is altered in patients with schizophrenia has not yet been studied in detail.

\section{Autism Spectrum Disorders}

Autism spectrum disorder (ASD) encompasses a group of severe neurodevelopmental disorders that exhibit core symptoms of social and communication deficits and stereotyped, repetitive behaviors (Association, 2013; Fein et al., 2021). Many studies highlight similar behavioral and cognitive impairments between ASD and schizophrenia such as social and language deficits and there is a high co-occurrence of both neurodevelopmental disorders (Spek and Wouters, 2010; King and Lord, 2011; Chisholm et al., 2015; Crescenzo et al., 2019). Based on this, it has been speculated that dysfunction in the DA system may also contribute to the cognitive disorders in ASD and, similar to schizophrenia, a DA hypothesis has been proposed for ASD. According to this hypothesis, aberrant mesocorticolimbic and nigrostriatal DA circuitry may contribute to reward deficits and goal-directed motor impairments manifested in ASD children (Pavăl, 2017; Pavăl and Micluţia, 2021). Initial evidence for impairments in the DA system in ASD came from a study that found elevated levels of DA metabolites, such as homovanillic acid, in the cerebrospinal fluid of autistic children (age 1- 16 years old) (Gillberg and Svennerholm, 1987). Further evidence supporting this hypothesis comes from (1) the discovery that de novo genetic variants of the gene encoding the dopamine transporter (DAT) (Neale et al., 2012; Hamilton et al., 2013; Bowton et al., 2014; Cartier et al., 2015) and gene polymorphisms in DRD3 and DRD4 (Gadow et al., 2010; Staal, 2014; Staal et al., 2015) are associated with ASD; (2) the therapeutic efficacy of DRD blockers (risperidone and aripiprazole) in alleviating stereotypic and/or abnormal social behaviors in children with autism (McCracken et al., 2002; McDougle et al., 2005; Ghaeli et al., 2014) and (3) studies showing that the reward circuitry is hypoactivated in autistic patients in response to social and monetary rewards (Zeeland et al., 2010; Dichter et al., 2012; Kohls et al., 2012). According to the DA hypothesis in ASD, this diminished ability to register rewards for social cues could lead to the decreased pursuit of social interaction and ultimately to the deficits in social and communication skills observed in ASD patients (Pavăl, 2017). Regarding the mesoprefrontal system, an early PET scanning study for fluorine-18-labeled fluorodopa (FDOPA) revealed significantly decreased F-DOPA ratio in the anterior $\mathrm{mPFC}$ of autistic children compared to healthy subjects, indicating decreased DA activity in the $\mathrm{MPFC}$ in autistic patients (Ernst et al., 1997). ASD patients underperform in working memory tasks involving planning, cognitive flexibility, and high working memory load compared to control subjects, which could be due to, or at least influenced by, a dysfunctional mesoprefrontal DA system (Kercood et al., 2014). Moreover, computational models predict that decreasing DA modulation in the PFC could lead to executive dysfunctions such as decreased cognitive flexibility, as occurs in ASD (Kriete and Noelle, 2015). Nevertheless, it remains largely unclear whether impairments of the mesoprefrontal DA system contribute to cognitive deficits in ASD patients and whether the development of mesoprefrontal $\mathrm{mDA}$ neurons is altered in ASD. The phenotypic heterogeneity 
of ASD and largely unknown disease mechanisms complicate the investigations of these potential deficits.

To uncover the potential role of altered development of the DA system and in particular the mesoprefrontal DA neurons in ASD etiology and associated social and executive dysfunctions, further DA system-focused studies in patients and ASD mouse models are needed. Evidence from mouse models for the involvement of the DA system in ASD is discussed in detail in a recent review (Kosillo and Bateup, 2021), thus we will only discuss two examples here. Mutations in the gene encoding SH3 and multiple ankyrin repeat domains 3 (SHANK3), a postsynaptic scaffolding protein, have been discovered in ASD patients, making it a prominent autism gene candidate (Gauthier et al., 2009; Phelan and McDermid, 2012; Boccuto et al., 2013). Studies on the Shank3 haploinsufficient mouse model show that impaired preference for social interactions is due to decreased DA activity in the VTA (Bariselli et al., 2016, 2018). Whether this hypoactivity results in decreased DA release in the nucleus accumbens and/or the mPFC has not yet been addressed. A potential link between autistic-like phenotypes and aberrant development of the DA system emerges from animal models for Mucopolysaccharidosis (MPS). MPS are hereditary lysosomal storage diseases, in which dysfunctions in lysosomal hydrolases lead to the accumulation of undegraded glycosaminoglycans in lysosomes and eventually to disturbances in cellular metabolism. In MPS IIIa, in which the gene coding for the lysosomal hydrolase sulfamidase is mutated, the metabolic cellular deficits result in neurodegeneration and dementia in children. Dementia is preceded by severe autistic-like behaviors (Valstar et al., 2010; Rumsey et al., 2014). In a mouse model of MPS IIIa, inactivation of the gene coding for sulfamidase, results in severely impaired behavior that that can be considered autism-like. These behavioral deficits are associated with increased DA release in the dorsal and ventral striatum and can be ameliorated with a DRD1 antagonist. This hyperdopaminergic state in MPS IIIa mice appears to be caused by developmental changes in the DA system: increased proliferation of $\mathrm{mDA}$ progenitors results in an increased number of $\mathrm{mDA}$ neurons in the SNpc and the VTA in the adult brain. Moreover, the same study shows that autisticlike behaviors and increased DA cell number are also present in a mouse model for a different type of MPS (MPS-II) (Risi et al., 2021). While this study suggests that altered development of the mDA system may be one of the causes of autism-like behaviors, it has not been investigated whether the increase in VTA neurons in these animal models leads also to alterations in the mesoprefrontal DA system. Further investigation of existing and potentially novel ASD candidate genes in animal models will be necessary to uncover developmental, structural, and/or functional impairments of the mesoprefrontal DA system in association with ASD.

\section{Attention Deficit Hyperactivity Disorder}

Attention deficit/hyperactivity disorder (ADHD) is a highly heritable, early-onset neurodevelopmental disorder, characterized by symptoms of hyperactivity, short attention span, and impulsivity. The PFC is a key region afflicted in this disorder. Studies report thinning of PFC areas, reduced density of the dorsolateral PFC, and decreased PFC activity in ADHD patients compared to controls (Arnsten and Pliszka, 2011; Cortese, 2012; Klein et al., 2019). Shaw and colleagues reported that the PFC in children with ADHD takes significantly longer to reach peak cortical thickness compared to the PFC in typically developing individuals, suggesting a delay in PFC maturation (Shaw et al., 2007a). The typical ADHD symptoms also reflect impaired executive functioning of PFC, which in turn is related to dysregulated NA and DA signaling in the PFC (Arnsten and Pliszka, 2011). There are several points of evidence that suggest that alterations in the DA system may contribute to ADHD symptoms. An F-DOPA PET study showed low DOPA-decarboxylase activity in the PFC of adult ADHD patients compared to healthy controls, an effect that could however not be replicated in adolescents with ADHD (Del Campo et al., 2011). Methylphenidate and amphetamine, which are used in the treatment of ADHD, act by inhibiting DA and NA reuptake and consequently by increasing DA and NA transmission in the PFC. Low doses of methylphenidate have been shown to improve PFC function in rats and monkeys, which can be counteracted by blocking DRD1 receptor. Moreover, mice heterozygous for the gene encoding dopamine transporter (DAT hypofunction mice), show behavior typical for ADHD such as hyperactivity, inattention, and impulsivity. Inattentive and impulsive behavior in these mice can be rescued by amphetamine. In humans, using radiolabeled altropane, a high-affinity selective probe for DAT, neuroimaging studies point towards evidence of increased DAT activity in striatum of children and adults with ADHD. However, due to its limited expression, it has been challenging to analyze DAT levels in the cortex using PET imaging techniques and it is still poorly characterized in the PFC of ADHD patients (Spencer et al., 2005; Prince, 2008). In addition, there is a significant association between ADHD and polymorphism in the genes that encode DRD4, DRD5, and DAT. DRD4 has a high number of polymorphisms in its nucleotide sequence. Comprehensive meta-analyses showed that the so-called DRD4 7-repeat allele (DRD4 7R; a 7-repeat form of the 48-base pair (bp) variable number tandem repeat) elevates the risk of ADHD (Wu et al., 2012). Shaw and colleagues showed that presence of DRD4 7R was linked to cortical thinning in orbitofrontal and inferior prefrontal cortex that was augmented in ADHD patients (Shaw et al., 2007b). Another study suggests a considerable reduction in gyrification of inferior frontal gyrus in children with ADHD, who were DRD4 7R allele carrier. The authors hypothesize that this DRD4 polymorphism could affect early stages of cortical development in children who later develop ADHD (Palaniyappan et al., 2019). Additionally, a 148-bp and a 136-bp dinucleotide repeat allele from the $D R D 5$ gene have also received considerable attention while the most extensively studied DAT polymorphism involves the 40 bp 9-repeat and 10-repeat alleles (Gizer et al., 2009; Wu et al., 2012).

An evolutionary perspective on ADHD argues for an adaptive role of the mesoprefrontal system in the disorder. Symptoms associated with ADHD, such as hyperactivity or limited sustained attention, could help animals to detect threats more rapidly and hence serve as beneficial features in endangered situations (Jensen et al., 1997; Lee and Goto, 2015). When 
delayed PFC maturation puts animals at a disadvantage in an adverse environment, ADHD symptoms arising from reduced mesoprefrontal DA could emerge as a compensative mechanism to make animals less vulnerable to the environmental threats. While such an adaptive response may have aided ancestral humans in stressful conditions, it does not translate well to modern social settings (Lee and Goto, 2015).

In summary, these data indicate that changes in DA signaling, in particular in the PFC may play a critical role in the pathophysiology of ADHD. However, it remains challenging to separate the impact of altered DA versus NA signaling on PFC dysfunction in ADHD. It also should be taken into consideration, that similar to schizophrenia and ASD, alterations in DA signaling could be secondary to functional changes in cortical areas (Arnsten and Dudley, 2005; Gamo et al., 2010; Arnsten and Pliszka, 2011; Mereu et al., 2017). The etiology of ADHD is multifaceted, having a strong genetic background but also contributions from environmental risk factors. Beside PFC, other brain regions having reciprocal connection to PFC, such as caudate and cerebellum are affected and there is an intricate interplay of neurotransmitters distinctive to each region (Arnsten and Pliszka, 2011; Cortese, 2012). Our understanding of the role of reduced mesoprefrontal signaling among these complex interactions is still evolving (Stanford and Heal, 2019) and requires further studies to better understand both, its specific function, and its complementary role along with DA signaling in the subcortical brain regions, in the pathophysiology of ADHD.

\section{CONCLUSION}

Research over the past decade has vastly increased our knowledge of the development of $\mathrm{mDA}$ neurons and their molecular and functional diversity. Despite these advances, fundamental questions about the development and function of the mesoprefrontal DA system remain unresolved. For example, it is still unclear whether mesoprefrontal mDA neurons arise from a specific $\mathrm{mDA}$ progenitor population during development and whether these neurons can be

\section{REFERENCES}

Abi-Dargham, A. (2017). A dual hit model for dopamine in schizophrenia. Biol. Psychiat. 81, 2-4. doi: 10.1016/j.biopsych.2016. 10.008

Allen Institute for Brain Science (2010). BrainSpan Atlas of the Developing Human Brain. Washington, DC: Allen Institute for Brain Science

Altman, J., and Bayer, S. A. (1981). Development of the brain stem in the rat. $\mathrm{V}$. Thymidine-radiographic study of the time of origin of neurons in the midbrain tegmentum. J. Comp. Neurol. 198, 677-716. doi: 10.1002/cne.9019 80409

Andersen, S. L., Thompson, A. T., Rutstein, M., Hostetter, J. C., and Teicher, M. H. (2000). Dopamine receptor pruning in prefrontal cortex during the periadolescent period in rats. Synapse 37, 167-169.

Andersson, E., Tryggvason, U., Deng, Q., Friling, S., Alekseenko, Z., Robert, B., et al. (2006). Identifica-tion of intrinsic determinants of midbrain dopamine neurons. Cell 124, 393-405. doi: 10.1016/j.cell.2005.10.037

Araki, K. Y., Sims, J. R., and Bhide, P. G. (2007). Dopamine receptor mRNA and protein expression in the mouse corpus striatum and cerebral cortex during pre- and postnatal development. Brain Res. 1156, 31-45. doi: 10.1016/j.brainres. 2007.04.043 defined at the molecular level as a specific mDA subset. Findings on the developmental history and molecular profile of these neurons would facilitate specific manipulation of the mesoprefrontal DA system by genetic methods (e.g., optogenetics, chemogenetics). This would allow to examine the consequences of functional changes in mesoprefrontal DA release on PFC development and PFC-regulated behavior. A possibility to specifically study the mesoprefrontal system during development and in the adult brain would most likely also provide further insights into a potential causative role of mesoprefrontal dysfunction in neurodevelopmental and neuropsychiatric disorders. Finally, how the mesoprefrontal system affects the activity of micronetworks in the PFC is still an open question, as it is still not fully understood at which stages, in which cell types and cortical layers DRDs are expressed in PFC and how DA release is coordinated with co-release of glutamate.

\section{AUTHOR CONTRIBUTIONS}

KI, NM, and SB: writing-original draft and review and editing. All authors contributed to the article and approved the submitted version.

\section{FUNDING}

This work was supported by the German Research Foundation [BL 767/5-1 (Project number: 417960915) to SB], the German Research Foundation SFB 1089 (to KI and SB) and the BONFOR program of the Medical Faculty, University of Bonn (O-154.0120, to NM and SB).

\section{SUPPLEMENTARY MATERIAL}

The Supplementary Material for this article can be found online at: https://www.frontiersin.org/articles/10.3389/fncir. 2021.746582/full\#supplementary-material

Aransay, A., Rodríguez-López, C., García-Amado, M., Clascá, F., and Prensa, L. (2015). Long-range pro-jection neurons of the mouse ventral tegmental area: a single-cell axon tracing analysis. Front. Neuroanat. 9:59. doi: 10.3389/fnana. 2015.00059

Arnsten, A. F. T., and Pliszka, S. R. (2011). Catecholamine influences on prefrontal cortical function: Rel-evance to treatment of attention deficit/hyperactivity disorder and related disorders. Pharmacol. Biochem. Behav. 99, 211-216. doi: 10.1016/j.pbb.2011.01.020

Arnsten, A. F., and Dudley, A. G. (2005). Methylphenidate improves prefrontal cortical cognitive function through alpha2 adrenoceptor and dopamine D1 receptor actions: Relevance to therapeutic effects in Attention Deficit Hyperactivity Disorder. Behav. Brain Funct. BBF 1:2. doi: 10.1186/1744-9081$1-2$

Ásgrímsdóttir, E. S., and Arenas, E. (2020). Midbrain dopaminergic neuron development at the single cell level: in vivo and in stem cells. Front. Cell Dev. Biol. 8:463. doi: 10.3389/fcell.2020.00463

Association, A. P. (2013). Diagnostic and Statistical Manual of Mental Disorders (DSM- 5), Fifth Edition, 5th Edn. Washington, DC: American Psychiatric Association Publishing

Bariselli, S., Contestabile, A., Tzanoulinou, S., Musardo, S., and Bellone, C. (2018). SHANK3 downregu-lation in the ventral tegmental area accelerates 
the extinction of contextual associations induced by juvenile non-familiar conspecific interaction. Front. Mol. Neurosci. 11:360. doi: 10.3389/fnmol.2018. 00360

Bariselli, S., Tzanoulinou, S., Glangetas, C., Prévost-Solié, C., Pucci, L., Viguié, J., et al. (2016). SHANK3 controls maturation of social reward circuits in the VTA. Nat. Neurosci. 19, 926-934. doi: 10.1038/nn.4319

Bayer, S. A., Wills, K. V., Triarhou, L. C., and Ghetti, B. (1995). Time of neuron origin and gradients of neurogenesis in midbrain dopaminergic neurons in the mouse. Exp. Brain Res. 105, 191-199. doi: 10.1007/bf00240955

Beaulieu, J.-M., Sotnikova, T. D., Marion, S., Lefkowitz, R. J., Gainetdinov, R. R., and Caron, M. G. (2005). An Akt/ $\beta$-Arrestin 2/PP2A signaling complex mediates dopaminergic neurotransmission and behavior. Cell 122, 261-273. doi: $10.1016 /$ j.cell.2005.05.012

Beier, K. T., Gao, X. J., Xie, S., DeLoach, K. E., Malenka, R. C., and Luo, L. (2019). Topological organi-zation of ventral tegmental area connectivity revealed by viral-genetic dissection of input-output relations. Cell Rep. 26, 159-167.e6. doi: 10.1016/j.celrep.2018.12.040

Beier, K. T., Steinberg, E. E., DeLoach, K. E., Xie, S., Miyamichi, K., Schwarz, L., et al. (2015). Circuit architecture of VTA dopamine neurons revealed by systematic input-output mapping. Cell 162, 622-634. doi: 10.1016/j.cell.2015. 07.015

Beil, J., Fairbairn, L., Pelczar, P., and Buch, T. (2012). Is BAC transgenesis obsolete? State of the art in the era of designer nucleases. J. Biomed. Biotechnol. 2012:308414. doi: 10.1155/2012/308414

Benes, F. M., Vincent, S. L., and Molloy, R. (1993). Dopamine-Immunoreactive axon varicosities form nonrandom contacts with GABA-immunoreactive neurons of rat medial prefrontal cortex. Synapse 14, 285-295. doi: 10.1002/syn. 890150405

Benes, F. M., Vincent, S. L., Molloy, R., and Khan, Y. (1996). Increased interaction of dopamine- immu-noreactive varicosities with GABA neurons of rat medial prefontal cortex occurs during the post-weanling period. Synapse 23, 237-245.

Bhattacherjee, A., Djekidel, M. N., Chen, R., Chen, W., Tuesta, L. M., and Zhang, Y. (2019). Cell type-specific transcriptional programs in mouse prefrontal cortex during adolescence and addiction. Nat. Commun. 10:4169. doi: 10.1038/s41467019-12054-3

Biol Psychiat (2017). Special issue: the dopamine hypothesis of schizophrenia. Biol. Psychiat. 81:1. doi: 10.1016/j.biopsych.2016.11.002

Blaess, S., and Ang, S. (2015). Genetic control of midbrain dopaminergic neuron development. Wiley Interdiscip. Rev. Dev. Biol. 4, 113-134. doi: 10.1002/ wdev.169

Blaess, S., Bodea, G. O., Kabanova, A., Chanet, S., Mugniery, E., Derouiche, A., et al. (2011). Temporal-spatial changes in Sonic Hedgehog expression and signaling reveal different potentials of ventral mesencephalic progenitors to populate distinct ventral midbrain nuclei. Neural Dev. 6:29. doi: 10.1186/1749-81 04-6-29

Boccuto, L., Lauri, M., Sarasua, S. M., Skinner, C. D., Buccella, D., Dwivedi, A., et al. (2013). Prevalence of SHANK3 variants in patients with different subtypes of autism spectrum disorders. Eur. J. Hum. Genet. 21, 310-316. doi: 10.1038/ ejhg.2012.175

Bodea, G. O., and Blaess, S. (2015). Establishing diversity in the dopaminergic system. FEBS Lett. 589, 3773-3785. doi: 10.1016/j.febslet.2015.09.016

Bodei, S., Arrighi, N., Spano, P., and Sigala, S. (2009). Should we be cautious on the use of commercially available antibodies to dopamine receptors? Naunyn Schmiedebergs Arch. Pharmacol. 379, 413-415. doi: 10.1007/s00210-0080384-6

Bordelon-Glausier, J. R., Khan, Z. U., and Muly, E. C. (2008). Quantification of D1 and D5 dopamine re-ceptor localization in layers I, III, and V of Macaca mulatta prefrontal cortical area 9: Coexpression in dendritic spines and axon terminals. J. Comp. Neurol. 508, 893-905. doi: 10.1002/cne.21710

Bowton, E., Saunders, C., Reddy, I. A., Campbell, N. G., Hamilton, P. J., Henry, L. K., et al. (2014). SLC6A3 coding variant Ala559Val found in two autism probands alters dopamine transporter function and trafficking. Transl. Psychiatry 4:e00464-64. doi: 10.1038/tp.2014.90

Boyson, S., McGonigle, P., and Molinoff, P. (1986). Quantitative autoradiographic localization of the D1 and D2 subtypes of dopamine receptors in rat brain. J. Neurosci. 6, 3177-3188. doi: 10.1523/jneurosci.06-11-03177.1986

Braun, U., Harneit, A., Pergola, G., Menara, T., Schäfer, A., Betzel, R. F., et al. (2021). Brain network dy-namics during working memory are modulated by dopamine and diminished in schizophrenia. Nat. Commun. 12:3478. doi: 10. 1038/s41467-021-23694-9
Brenhouse, H. C., Sonntag, K. C., and Andersen, S. L. (2008). Transient D1 dopamine receptor expres-sion on prefrontal cortex projection neurons: relationship to enhanced motivational salience of drug cues in adolescence. J. Neurosci. 28, 2375-2382. doi: 10.1523/jneurosci.5064-07.2008

Brignani, S., and Pasterkamp, R. J. (2017). Neuronal subset-specific migration and axonal wiring mech-anisms in the developing midbrain dopamine system. Front. Neuroanat. 11:55. doi: 10.3389/fnana.2017.00055

Bye, C. R., Thompson, L. H., and Parish, C. L. (2012). Birth dating of midbrain dopamine neurons identi-fies A9 enriched tissue for transplantation into Parkinsonian mice. Exp. Neurol. 236, 58-68. doi: 10.1016/j.expneurol.2012. 04.002

Caballero, A., and Tseng, K. Y. (2016). GABAergic function as a limiting factor for prefrontal maturation during adolescence. Trends Neurosci. 39, 441-448. doi: 10.1016/j.tins.2016.04.010

Carlén, M. (2017). What constitutes the prefrontal cortex? Science 358, 478-482. doi: $10.1126 /$ science.aan 8868

Cartier, E., Hamilton, P. J., Belovich, A. N., Shekar, A., Campbell, N. G., Saunders, C., et al. (2015). Rare autism-associated variants implicate syntaxin 1 (STX1 R26Q) phosphorylation and the dopamine transporter (hDAT R51W) in dopamine neurotransmission and behaviors. Ebiomedicine 2, 135-146. doi: 10 . 1016/j.ebiom.2015.01.007

Chini, M., and Hanganu-Opatz, I. L. (2020). Prefrontal cortex development in health and disease: les-sons from rodents and humans. Trends Neurosci. 44, 227-240. doi: 10.1016/j.tins.2020.10.017

Chisholm, K., Lin, A., Abu-Akel, A., and Wood, S. J. (2015). The association between autism and schizo-phrenia spectrum disorders: A review of eight alternate models of co-occurrence. Neurosci. Biobehav. Rev. 55, 173-183. doi: 10.1016/j.neubiorev.2015.04.012

Chuhma, N., Mingote, S., Kalmbach, A., Yetnikoff, L., and Rayport, S. (2017). Heterogeneity in dopamine neuron synaptic actions across the striatum and its relevance for schizophrenia. Biol. Psychiatry 81, 43-51. doi: 10.1016/j.biopsych. 2016.07.002

Chun, L. S., Free, R. B., Doyle, T. B., Huang, X.-P., Rankin, M. L., and Sibley, D. R. (2013). D1-D2 do-pamine receptor synergy promotes calcium signaling via multiple mechanisms. Mol. Pharmacol. 84, 190-200. doi: 10.1124/mol.113. 085175

Ciliax, B. J., Nash, N., Heilman, C., Sunahara, R., Hartney, A., Tiberi, M., et al. (2000). Dopamine D5 re-ceptor immunolocalization in rat and monkey brain. Synapse 37, 125-145.

Clancy, B., Darlington, R. B., and Finlay, B. L. (2001). Translating developmental time across mammalian species. Neuroscience 105, 7-17. doi: 10.1016/s03064522(01)00171-3

Cortese, S. (2012). The neurobiology and genetics of AttentionDeficit/Hyperactivity Disorder (ADHD): What every clinician should know. Eur. J. Paediatr Neurol. 16, 422-433. doi: 10.1016/j.ejpn.2012.01.009

Crescenzo, F. D., Postorino, V., Siracusano, M., Riccioni, A., Armando, M., Curatolo, P., et al. (2019). Autistic symptoms in schizophrenia spectrum disorders: a systematic review and meta-analysis. Front. Psychiatry 10:78. doi: $10.3389 /$ fpsyt.2019.00078

Del Campo, N., Chamberlain, S. R., Sahakian, B. J., and Robbins, T. W. (2011). The roles of dopamine and noradrenaline in the pathophysiology and treatment of attention-deficit/hyperactivity disorder. Biol. Psychiatry 69:e00145-57. doi: 10.1016/j.biopsych.2011.02.036

Dichter, G. S., Richey, J. A., Rittenberg, A. M., Sabatino, A., and Bodfish, J. W. (2012). Reward circuitry function in autism during face anticipation and outcomes. J. Autism Dev. Disord. 42, 147-160. doi: 10.1007/s10803-011-1221-1

Dumas, S., and Wallén-Mackenzie, A (2019). Developmental co-expression of Vglut2 and Nurr1 in a mes-di-encephalic continuum preceeds dopamine and glutamate neuron specification. Front. Cell Dev. Biol. 7:307. doi: 10.3389/fcell. 2019.00307

Engelhard, B., Finkelstein, J., Cox, J., Fleming, W., Jang, H. J., Ornelas, S., et al. (2019). Specialized coding of sensory, motor and cognitive variables in VTA dopamine neurons. Nature 570, 509-513. doi: 10.1038/s41586-0191261-9

Ernst, M., Zametkin, A., Matochik, J., Pascualvaca, D., and Cohen, R. (1997). Low medial prefrontal do-paminergic activity in autistic children. Lancet 350:638. doi: 10.1016/s0140-6736(05)63326-0

Fan, X., Dong, J., Zhong, S., Wei, Y., Wu, Q., Yan, L., et al. (2018). Spatial transcriptomic survey of hu-man embryonic cerebral cortex by single-cell RNA-seq analysis. Cell Res. 28, 730-745. doi: 10.1038/s41422-018-0053-3 
Fan, X., Fu, Y., Zhou, X., Sun, L., Yang, M., Wang, M., et al. (2020). Singlecell transcriptome analysis reveals cell lineage specification in temporal-spatial patterns in human cortical development. Sci. Adv. 6:eaaz2978. doi: 10.1126/ sciadv.aaz2978

Fang, H., Bygrave, A. M., Roth, R. H., Johnson, R. C., and Huganir, R. L. (2021). An optimized CRISPR/Cas9 approach for precise genome editing in neurons. Elife 10:e65202. doi: 10.7554/elife.65202

Fein, R. H., Venta, A., Meinert, A. C., Mire, S. S., and Bergez, K. (2021). “Autism spectrum disorder," in Developmental Psychopathology, eds A. Venta, C. Sharp, J. M. Fletcher, and P. Fonagy (Hoboken, NJ: John Wiley \& Sons, Inc), 119-156. doi: 10.1002/9781118686089.ch6

Franco, S. J., and Müller, U. (2013). Shaping our minds: stem and progenitor cell diversity in the mam-malian neocortex. Neuron 77, 19-34. doi: 10.1016/j. neuron.2012.12.022

Freeman, T. B., Spence, M. S., Boss, B. D., Spector, D. H., Strecker, R. E., Olanow, C. W., et al. (1991). Development of dopaminergic neurons in the human substantia nigra. Exp. Neurol. 113, 344-353. doi: 10.1016/0014-4886(91)90025-8

Gadow, K. D., DeVincent, C. J., Olvet, D. M., Pisarevskaya, V., and Hatchwell, E. (2010). Association of DRD4 polymorphism with severity of oppositional defiant disorder, separation anxiety disorder and repetitive behaviors in children with autism spectrum disorder. Eur. J. Neurosci. 32, 1058-1065. doi: 10.1111/j.1460-9568.2010.07382.x

Gamo, N. J., Wang, M., and Arnsten, A. F. T. (2010). Methylphenidate and atomoxetine enhance prefron-tal function through $\alpha 2$-adrenergic and dopamine D1 receptors. J. Am. Acad. Child Adolesc. Psychiatry 49, 1011-1023. doi: $10.1016 /$ j.jaac.2010.06.015

Garcia, L. P., Witteveen, J. S., Middelman, A., van Hulten, J. A., Martens, G. J. M., Homberg, J. R., et al. (2019). Perturbed developmental serotonin signaling affects prefrontal catecholaminergic innerva-tion and cortical integrity. Mol. Neurobiol. 56, 1405-1420. doi: 10.1007/s12035-018-1105-x

Gaspar, P., Berger, B., Febvret, A., Vigny, A., and Henry, J. (1989). Catecholamine innervation the hu-man cerebral cortex as revealed comparative immunohistochemistry tyrosine hydroxylase and do-pamine-Beta-H ydroxylase. J. Comp. Neurol. 279, 249-271. doi: 10.1002/cne.902790208

Gaspar, P., Bloch, B., and Moine, C. (1995). D1 and D2 receptor gene expression in the rat frontal cortex: cellular localization in different classes of efferent neurons. Eur. J. Neurosci. 7, 1050-1063. doi: 10.1111/j.1460-9568.1995.tb01092.x

Gauthier, J., Spiegelman, D., Piton, A., Lafrenière, R. G., Laurent, S., St-Onge, J., et al. (2009). Novel de novo SHANK3 mutation in autistic patients. Am. J. Med. Genet. Part B Neuropsychiatr. Genet. 150B, 421-424. doi: 10.1002/ajmg.b.30822

Ghaeli, P., Nikvarz, N., Alaghband-Rad, J., Alimadadi, A., and Tehrani-Doost, M. (2014). Effects of risperidone on core symptoms of autistic disorder based on childhood autism rating scale: an open label study. Indian J. Psychol. Med. 36, 66-70. doi: 10.4103/0253-7176.127254

Gillberg, C., and Svennerholm, L. (1987). CSF monoamines in autistic syndromes and other pervasive developmental disorders of early childhood. Br. J. Psychiatry 151, 89-94. doi: 10.1192/bjp.151.1.89

Gizer, I. R., Ficks, C., and Waldman, I. D. (2009). Candidate gene studies of ADHD: a meta-analytic re-view. Hum. Genet. 126, 51-90. doi: 10.1007/s00439-009-0694-x

Goldman-Rakic, P. S., and Brown, R. M. (1982). Postnatal development of monoamine content and syn-thesis in the cerebral cortex of rhesus monkeys. Dev. Brain Res. 4, 339-349. doi: 10.1016/0165-3806(82)90146-8

Goldman-Rakic, P. S., Leranth, C., Williams, S. M., Mons, N., and Geffard, M. (1989). Dopamine synaptic complex with pyramidal neurons in primate cerebral cortex. Proc. Natl. Acad. Sci. U.S.A. 86, 9015-9019. doi: 10.1073/pnas.86.22.9015

Gong, S., Doughty, M., Harbaugh, C. R., Cummins, A., Hatten, M. E., Heintz, N., et al. (2007). Targeting cre recombinase to specific neuron populations with bacterial artificial chromosome constructs. J. Neurosci. 27, 9817-9823. doi: 10.1523/jneurosci.2707-07.2007

Gong, S., Zheng, C., Doughty, M. L., Losos, K., Didkovsky, N., Schambra, U. B., et al. (2003). A gene expression atlas of the central nervous system based on bacterial artificial chromosomes. Nature 425, 917-925. doi: $10.1038 /$ nature 02033
Grace, A. A. (2016). Dysregulation of the dopamine system in the pathophysiology of schizophrenia and depression. Nat. Rev. Neurosci. 17, 524-532. doi: $10.1038 /$ nrn.2016.57

Grace, A. A. (2017). Dopamine system dysregulation and the pathophysiology of schizophrenia: insights from the methylazoxymethanol acetate model. Biol. Psychiatry 81, 5-8. doi: 10.1016/j.biopsych.2015.11.007

Hamilton, P. J., Campbell, N. G., Sharma, S., Erreger, K., Hansen, F. H., Saunders, C., et al. (2013). De novo mutation in the dopamine transporter gene associates dopamine dysfunction with autism spec-trum disorder. Mol. Psychiatry 18, 1315-1323. doi: 10.1038/mp.2013.102

Hayes, L., Zhang, Z., Albert, P., Zervas, M., and Ahn, S. (2011). Timing of Sonic hedgehog and Glil ex-pression segregates midbrain dopamine neurons. J. Comp. Neurol. 519, 3001-3018. doi: 10.1002/cne.22711

Hisahara, S., and Shimohama, S. (2011). Dopamine receptors and Parkinson's disease. Int. J. Med. Chem. 2011, 1-16. doi: 10.1155/2011/403039

Hoops, D., and Flores, C. (2017). Making dopamine connections in adolescence. Trends Neurosci. 40, 709-719. doi: 10.1016/j.tins.2017.09.004

Iversen, L., Iversen, S., Dunnett, S., and Bjöklund, A. eds (2009). Dopamine Handbook. Oxford: Oxford University Press, doi: 10.1093/acprof: oso/9780195373035.001.0001

Jensen, P. S., Mrazek, D., Knapp, P. K., Steinberg, L., Pfeffer, C., Schowalter, J., et al. (1997). Evolution and revolution in child psychiatry. J. Am. Acad. Child Adolesc. Psychiatry 36, 1672-1681. doi: 10.1097/00004583-199712000-00015

Joksimovic, M., Anderegg, A., Roy, A., Campochiaro, L., Yun, B., Kittappa, R., et al. (2009). Spatiotemporally separable Shh domains in the midbrain define distinct dopaminergic progenitor pools. Proc. Natl. Acad. Sci. U.S.A. 106, 19185-19190. doi: 10.1073/pnas.0904285106

Kaasinen, V., Vilkman, H., Hietala, J., Någren, K., Helenius, H., Olsson, $\mathrm{H}$, et al. (2000). Age-related do-pamine D2/D3 receptor loss in extrastriatal regions of the human brain. Neurobiol. Aging 21, 683-688. doi: 10.1016/s0197-4580(00)00149-4

Kabanova, A., Pabst, M., Lorkowski, M., Braganza, O., Boehlen, A., Nikbakht, N., et al. (2015). Function and developmental origin of a mesocortical inhibitory circuit. Nat. Neurosci. 18, 872-882. doi: 10.1038/nn.4020

Kalsbeek, A., Voorn, P., Buijs, R. M., Pool, C. W., and Uylings, H. B. M. (1988). Development of the do-paminergic innervation in the prefrontal cortex of the rat. J. Comp. Neurol. 269, 58-72. doi: 10.1002/cne.902690105

Kercood, S., Grskovic, J. A., Banda, D., and Begeske, J. (2014). Working memory and autism: a review of literature. Res. Autism Spect. Dis. 8, 1316-1332. doi: 10.1016/j.rasd.2014.06.011

Kim, J.-Y., and Paredes, M. F. (2021). Implications of extended inhibitory neuron development. Int. J. Mol. Sci. 22:5113. doi: 10.3390/ijms22105113

King, B. H., and Lord, C. (2011). Is schizophrenia on the autism spectrum? Brain Res. 1380, 34-41. doi: 10.1016/j.brainres.2010.11.031

Klein, M. O., Battagello, D. S., Cardoso, A. R., Hauser, D. N., Bittencourt, J. C., and Correa, R. G. (2019). Dopamine: functions, signaling, and association with neurological diseases. Cell. Mol. Neurobiol. 39, 31-59. doi: 10.1007/s10571-018-0632-3

Kohls, G., Schulte-Rüther, M., Nehrkorn, B., Müller, K., Fink, G. R., Kamp-Becker, I., et al. (2012). Reward system dysfunction in autism spectrum disorders. Soc. Cogn. Affect. Neurosci. 8, 565-572. doi: 10.1093/scan/nss033

Kolk, S. M., Gunput, R.-A. F., Tran, T. S., van den Heuvel, D. M. A., Prasad, A. A., Hellemons, A. J. C. G. M., et al. (2009). Semaphorin 3 F is a bifunctional guidance cue for dopaminergic axons and con-trols their fasciculation, channeling, rostral growth, and intracortical targeting. J. Neurosci. 29, 12542-12557. doi: 10.1523/jneurosci.2521-09.2009

Kosillo, P., and Bateup, H. S. (2021). Dopaminergic dysregulation in syndromic autism spectrum disor-ders: insights from genetic mouse models. Front. Neural Circuits 15:68. doi: 10.3389/fncir.2021.700968

Kouwenhoven, W., Fortin, G., Penttinen, A., Florence, C., Delignat-Lavaud, B., Bourque, M., et al. (2020). VGluT2 expression in dopamine neurons contributes to postlesional striatal reinnervation. J. Neurosci. 40, 8262-8275. doi: 10.1523/JNEUROSCI.0823-20.2020

Kriete, T., and Noelle, D. C. (2015). Dopamine and the development of executive dysfunction in autism spectrum disorders. PLoS One 10:e121605. doi: 10.1371/journal.pone.0121605 
Labouesse, M. A., Cola, R. B., and Patriarchi, T. (2020). GPCR-Based dopamine sensors-a detailed guide to inform sensor choice for in vivo imaging. Int. J. Mol. Sci. 21:8048. doi: 10.3390/ijms21218048

Lammel, S., Ion, D. I., Roeper, J., and Malenka, R. C. (2011). Projection-Specific modulation of dopamine neuron synapses by aversive and rewarding stimuli. Neuron 70, 855-862. doi: 10.1016/j.neuron.2011.03.025

Lammel, S., Lim, B. K., Ran, C., Huang, K. W., Betley, M. J., Tye, K. M., et al. (2012). Input-specific con-trol of reward and aversion in the ventral tegmental area. Nature 491, 212-217. doi: 10.1038/nature11527

Landwehrmeyer, B., Mengod, G., and Palacios, J. M. (1993). Differential visualization of dopamine D2 and D3 receptor sites in rat brain. a comparative study using in situ hybridization histochemistry and ligand binding autoradiography. Eur. J. Neurosci. 5, 145-153. doi: 10.1111/j.1460-9568.1993.tb00480.x

Laubach, M., Amarante, L. M., Swanson, T. K., and White, S. R. (2018). What, if anything, is rodent pre-frontal cortex? Eneuro 5:ENEURO.0315-18.2018. doi: 10.1523/eneuro.0315-18.2018

Lavin, A., Nogueira, L., Lapish, C. C., Wightman, R. M., Phillips, P. E. M., and Seamans, J. K. (2005). Mesocortical dopamine neurons operate in distinct temporal domains using multimodal signaling. J. Neurosci. 25, 5013-5023. doi: 10.1523/jneurosci.0557-05.2005

Lee, S. J., Lodder, B., Chen, Y., Patriarchi, T., Tian, L., and Sabatini, B. L. (2021). Cell-type-specific asynchronous modulation of PKA by dopamine in learning. Nature 590, 451-456. doi: 10.1038/s41586-020-03050-5

Lee, S. P., So, C. H., Rashid, A. J., Varghese, G., Cheng, R., Lança, A. J., et al. (2004). Dopamine D1 and D2 receptor co-activation generates a novel phospholipase c-mediated calcium signal*. J. Biol. Chem. 279, 35671-35678. doi: $10.1074 / j b c . m 401923200$

Lee, Y.-A., and Goto, Y. (2015). Prefrontal cortical dopamine from an evolutionary perspective. Neurosci. Bull. 31, 164-174. doi: 10.1007/s12264-014-1499-z

Leslie, C. A., Robertson, M. W., Cutler, A. J., and Bennett, J. P. (1991). Postnatal development of D 1 dopamine receptors in the medial prefrontal cortex, striatum and nucleus accumbens of normal and neonatal 6-hydroxydopamine treated rats: a quantitative autoradiographic analysis. Dev. Brain Res. 62, 109-114. doi: 10.1016/0165-3806(91)90195-o

Levey, A. I., Hersch, S. M., Rye, D. B., Sunahara, R. K., Niznik, H. B., Kitt, C. A., et al. (1993). Localiza-tion of D1 and D2 dopamine receptors in brain with subtype-specific antibodies. Proc. Natl. Acad. Sci. U.S.A. 90, 8861-8865. doi: 10.1073/pnas.90.19.8861

Levitt, P., and Moore, R. (1979). Development of the noradrenergic innervation of neocortex. Brain Res. 162, 243-259. doi: 10.1016/0006-8993(79)90287-7

Levitt, P., and Rakic, P. (1982). The time of genesis, embryonic origin and differentiation of the brain stem monoamine neurons in the rhesus monkey. Dev. Brain Res. 4, 35-57. doi: 10.1016/0165-3806(82)90095-5

Lewis, D. A., and Harris, H. W. (1991). Differential laminar distribution of tyrosine hydroxylase-immunoreactive axons in infant and adult monkey prefrontal cortex. Neurosci. Lett. 125, 151-154. doi: 10.1016/0304-3940(91)90014-k

Lewitus, E., Kelava, I., Kalinka, A. T., Tomancak, P., and Huttner, W. B. (2014). An adaptive threshold in mammalian neocortical evolution. PLoS Biol. 12:e1002000. doi: 10.1371/journal.pbio. 1002000

Li, Y., and Kuzhikandathil, E. V. (2012). Molecular characterization of individual D3 dopamine receptor-expressing cells isolated from multiple brain regions of a novel mouse model. Brain Struct. Funct. 217, 809-833. doi: $10.1007 / \mathrm{s} 00429-012-0383-8$

Lidow, M. S., and Rakic, P. (1992). Scheduling of monoaminergic neurotransmitter receptor expression in the primate neocortex during postnatal development. Cereb. Cortex 2, 401-416. doi: 10.1093/cercor/2.5.401

Lidow, M. S., Koh, P., and Arnsten, A. F. T. (2003). D1 dopamine receptors in the mouse prefrontal cor-tex: Immunocytochemical and cognitive neuropharmacological analyses. Synapse 47, 101-108. doi: 10.1002/syn.10143

Lim, L., Mi, D., Llorca, A., and Marín, O. (2018). Development and functional diversification of cortical interneurons. Neuron 100, 294-313. doi: 10.1016/j.neuron.2018.10.009

Lui, J. H., Hansen, D. V., and Kriegstein, A. R. (2011). Development and evolution of the human neocor-tex. Cell 146, 18-36. doi: 10.1016/j.cell.2011.06.030

Macosko, E. Z., Basu, A., Satija, R., Nemesh, J., Shekhar, K., Goldman, M., et al. (2015). Highly parallel genome-wide expression profiling of individual cells using nanoliter droplets. Cell 161, 1202-1214. doi: 10.1016/j.cell.2015.05.002
Madisen, L., Zwingman, T. A., Sunkin, S. M., Oh, S. W., Zariwala, H. A., $\mathrm{Gu}, \mathrm{H}$., et al. (2010). A robust and high-throughput Cre reporting and characterization system for the whole mouse brain. Nat. Neurosci. 13, 133-140. doi: $10.1038 / \mathrm{nn} .2467$

Marder, S. R., and Cannon, T. D. (2019). Schizophrenia. N. Engl. J. Med. 381, 1753-1761. doi: 10.1056/nejmra1808803

Marotta, R., Risoleo, M. C., Messina, G., Parisi, L., Carotenuto, M., Vetri, L., et al. (2020). The neuro-chemistry of autism. Brain Sci. 10:163. doi: $10.3390 /$ brainsci10030163

Maynard, K. R., Collado-Torres, L., Weber, L. M., Uytingco, C., Barry, B. K., Williams, S. R., et al. (2021). Transcriptome-scale spatial gene expression in the human dorsolateral prefrontal cortex. Nat. Neurosci. 24, 425-436. doi: 10.1038/s41593-020-00787-0

McCracken, J. T., McGough, J., Shah, B., Cronin, P., Hong, D., Aman, M. G., et al. (2002). Risperidone in children with autism and serious behavioral problems. N. Engl. J. Med. 347, 314-321. doi: 10.1056/nejmoa013171

McDougle, C. J., Scahill, L., Aman, M. G., McCracken, J. T., Tierney, E., Davies, M., et al. (2005). Risper-idone for the core symptom domains of autism: results from the study by the autism network of the research units on pediatric psychopharmacology. Am. J. Psychiatry 162, 1142-1148. doi: 10.1176/appi.ajp.162.6.1142

Menegas, W., Akiti, K., Amo, R., Uchida, N., and Watabe-Uchida, M. (2018). Dopamine neurons project-ing to the posterior striatum reinforce avoidance of threatening stimuli. Nat. Neurosci. 21, 1421-1430. doi: 10.1038/s41593-018-0222-1

Mereu, M., Contarini, G., Buonaguro, E. F., Latte, G., Managò, F., Iasevoli, F., et al. (2017). Dopamine transporter (DAT) genetic hypofunction in mice produces alterations consistent with ADHD but not schizophrenia or bipolar disorder. Neuropharmacology 121, 179-194. doi: 10.1016/j.neuropharm.2017.04.037

Mesman, S., von Oerthel, L., and Smidt, M. P. (2014). Mesodiencephalic dopaminergic neuronal differ-entiation does not involve GLI2A-Mediated SHH-signaling and is under the direct influence of ca-nonical WNT signaling. PLoS One 9:e97926. doi: 10.1371/journal.pone.0097926

Mingote, S., Chuhma, N., Kusnoor, S. V., Field, B., Deutch, A. Y., and Rayport, S. (2015). Functional connectome analysis of dopamine neuron glutamatergic connections in forebrain regions. J. Neurosci. 35, 16259-16271. doi: 10.1523/jneurosci.1674-15.2015

Miškiæ, T., Kostoviæ, I., Rašin, M.-R., and Krsnik, Ž (2021). Adult upper cortical layer specific transcrip-tion factor CUX2 is expressed in transient subplate and marginal zone neurons of the developing human brain. Cells 10:415. doi: $10.3390 /$ cells 10020415

Missale, C., Nash, S. R., Robinson, S. W., Jaber, M., and Caron, M. G. (1998). Dopamine receptors: from structure to function. Physiol. Rev. 78, 189-225. doi: 10.1152/physrev.1998.78.1.189

Mukhtar, T., and Taylor, V. (2018). Untangling cortical complexity during development. J. Exp. Neurosci. 12:1179069518759332. doi: $10.1177 / 1179069518759332$

Nakamura, S., Ito, Y., Shirasaki, R., and Murakami, F. (2000). Local directional cues control growth po-larity of dopaminergic axons along the rostrocaudal axis. J. Neurosci. 20, 4112-4119. doi: 10.1523/jneurosci.20-11-04112. 2000

Naneix, F., Marchand, A. R., Scala, G. D., Pape, J.-R., and Coutureau, E. (2012). Parallel maturation of goal-directed behavior and dopaminergic systems during adolescence. J. Neurosci. 32, 16223-16232. doi: 10.1523/jneurosci.3080-12.2012

Navandar, M., Martín-García, E., Maldonado, R., Lutz, B., Gerber, S., and de Azua, I. R. (2021). Tran-scriptional signatures in prefrontal cortex confer vulnerability versus resilience to food and cocaine addiction-like behavior. Sci. Rep. 11:9076. doi: 10.1038/s41598-021-88363-9

Neale, B. M., Kou, Y., Liu, L., Ma’ayan, A., Samocha, K. E., Sabo, A., et al. (2012). Patterns and rates of exonic de novo mutations in autism spectrum disorders. Nature 485, 242-245. doi: 10.1038/nature11011

Noaín, D., Avale, M. E., Wedemeyer, C., Calvo, D., Peper, M., and Rubinstein, M. (2006). Identification of brain neurons expressing the dopamine D4 receptor gene using BAC transgenic mice. Eur. J. Neurosci. 24, 2429-2438. doi: 10.1111/j.1460-9568.2006.05148.x

Noisin, E. L., and Thomas, W. E. (1988). Ontogeny of dopaminergic function in the rat midbrain tegmen-tum, corpus striatum and frontal cortex. Dev. Brain Res. 41, 241-252. doi: 10.1016/0165-3806(88)90186-1 
Palaniyappan, L., Batty, M. J., Liddle, P. F., Liddle, E. B., Groom, M. J., Hollis, C., et al. (2019). Reduced prefrontal gyrification in carriers of the dopamine D4 receptor 7-Repeat allele with attention deficit/hyperactivity disorder: a preliminary report. Front. Psychiatry 10:235. doi: 10.3389/fpsyt.2019.00235

Panman, L., Papathanou, M., Laguna, A., Oosterveen, T., Volakakis, N., Acampora, D., et al. (2014). Sox6 and Otx2 control the specification of substantia nigra and ventral tegmental area dopamine neurons. Cell Rep. 8, 1018-1025. doi: 10.1016/j.celrep.2014.07.016

Paredes, M. F., James, D., Gil-Perotin, S., Kim, H., Cotter, J. A., Ng, C., et al. (2016). Extensive migration of young neurons into the infant human frontal lobe. Science 354:aaf7073. doi: 10.1126/science.aaf7073

Pastor, V., and Medina, J. H. (2021). Medial prefrontal cortical control of rewardand aversion-based behavioral output: Bottom-up modulation. Eur. J. Neurosci. 53, 3039-3062. doi: 10.1111/ejn.15168

Pavăl, D. (2017). A dopamine hypothesis of autism spectrum disorder. Dev. Neurosci. 39, 355-360. doi: 10.1159/000478725

Pavăl, D., and Micluţia, I. V. (2021). The dopamine hypothesis of autism spectrum disorder revisited: current status and future prospects. Dev. Neurosci. 43, 73-83. doi: 10.1159/000515751

Pérez-López, J. L., Contreras-López, R., Ramírez-Jarquín, J. O., and Tecuapetla, F. (2018). Direct glu-tamatergic signaling from midbrain dopaminergic neurons onto pyramidal prefrontal cortex neu-rons. Front. Neural Circuit 12:70. doi: $10.3389 /$ fncir.2018.00070

Phelan, K., and McDermid, H. E. (2012). The 22q13.3 deletion syndrome (PhelanMcDermid Syndrome). Mol. Syndromol. 2, 186-201. doi: 10.1159/000334260

Polioudakis, D., de la Torre-Ubieta, L., Langerman, J., Elkins, A. G., Shi, X., Stein, J. L., et al. (2019). A single-cell transcriptomic atlas of human neocortical development during mid-gestation. Neuron 103, 785-801.e8. doi: 10.1016/j.neuron.2019.06.011

Poulin, J.-F., Caronia, G., Hofer, C., Cui, Q., Helm, B., Ramakrishnan, C., et al. (2018). Mapping projec-tions of molecularly defined dopamine neuron subtypes using intersectional genetic approaches. Nat. Neurosci. 21, 1260-1271. doi: 10.1038/s41593-018-0203-4

Poulin, J.-F., Gaertner, Z., Moreno-Ramos, O. A., and Awatramani, R. (2020). Classification of midbrain dopamine neurons using single-cell gene expression profiling approaches. Trends Neurosci. 43, 155-169. doi: 10.1016/j.tins.2020.01.004

Prince, J. (2008). Catecholamine dysfunction in attention-deficit/hyperactivity disorder: an update. J. Clin. Psychopharm. 28, S39-S45. doi: 10.1097/jcp. 0b013e318174f92a

Raghanti, M. A., Stimpson, C. D., Marcinkiewicz, J. L., Erwin, J. M., Hof, P. R., and Sherwood, C. C. (2008). Cortical dopaminergic innervation among humans, chimpanzees, and macaque monkeys: A comparative study. Neuroscience 155, 203-220. doi: 10.1016/j.neuroscience.2008.05.008

Rajput, P. S., Kharmate, G., Somvanshi, R. K., and Kumar, U. (2009). Colocalization of dopamine recep-tor subtypes with dopamine and cAMPregulated phosphoprotein (DARPP-32) in rat brain. Neurosci. Res. 65, 53-63. doi: 10.1016/j.neures.2009.05.005

Reynolds, L. M., Pokinko, M., Torres-Berrío, A., Cuesta, S., Lambert, L. C., Pellitero, E. D. C., et al. (2018). DCC receptors drive prefrontal cortex maturation by determining dopamine axon targeting in adolescence. Biol. Psychiatry 83, 181-192. doi: 10.1016/j.biopsych.2017.06.009

Rice, M. W., Roberts, R. C., Melendez-Ferro, M., and Perez-Costas, E. (2016). Mapping dopaminergic deficiencies in the substantia nigra/ventral tegmental area in schizophrenia. Brain Struct. Funct. 221, 185-201. doi: 10.1007/s00429-014-0901-y

Risi, M. D., Tufano, M., Alvino, F. G., Ferraro, M. G., Torromino, G., Gigante, Y., et al. (2021). Altered heparan sulfate metabolism during development triggers dopamine-dependent autistic-behaviours in models of lysosomal storage disorders. Nat. Commun. 12:3495. doi: 10.1038/s41467-021-23903-5

Root, D. H., Wang, H.-L., Liu, B., Barker, D. J., Mód, L., Szocsics, P., et al. (2016). Glutamate neurons are intermixed with midbrain dopamine neurons in nonhuman primates and humans. Sci. Rep. 6:30615. doi: 10.1038/srep30615

Rosenberg, D. R., and Lewis, D. A. (1995). Postnatal maturation of the dopaminergic innervation of mon-key prefrontal and motor cortices: A tyrosine hydroxylase immunohistochemical analysis. J. Comp. Neurol. 358, 383-400. doi: 10.1002/cne.903580306
Rothmond, D. A., Weickert, C. S., and Webster, M. J. (2012). Developmental changes in human dopa-mine neurotransmission: cortical receptors and terminators. BMC Neurosci. 13:18. doi: 10.1186/1471-2202-13-18

Rumsey, R. K., Rudser, K., Delaney, K., Potegal, M., Whitley, C. B., and Shapiro, E. (2014). Acquired autistic behaviors in children with mucopolysaccharidosis type IIIA. J. Pediatrics 164:1147-1151.e1. doi: 10.1016/j.jpeds.2014.01.007

Santana, N., and Artigas, F. (2017). Laminar and cellular distribution of monoamine receptors in rat medial prefrontal cortex. Front. Neuroanat. 11:87. doi: 10.3389/fnana.2017.00087

Santana, N., Mengod, G., and Artigas, F. (2009). Quantitative analysis of the expression of dopamine D1 and D2 receptors in pyramidal and GABAergic neurons of the rat prefrontal cortex. Cereb. Cortex 19, 849-860. doi: 10.1093/cercor/bhn134

Saunders, B. T., Richard, J. M., Margolis, E. B., and Janak, P. H. (2018). Dopamine neurons create Pav-lovian conditioned stimuli with circuit-defined motivational properties. Nat. Neurosci. 21, 1072-1083. doi: 10.1038/s41593-018-0191-4

Schambra, U. B., Duncan, G. E., Breese, G. R., Fornaretto, M. G., Caron, M. G., and Fremeau, R. T. (1994). Ontogeny of D1a and D2 dopamine receptor subtypes in rat brain using in situ hybridization and receptor binding. Neuroscience 62, 65-85. doi: 10.1016/0306-4522(94)90315-8

Schubert, D., Martens, G. J. M., and Kolk, S. M. (2015). Molecular underpinnings of prefrontal cortex development in rodents provide insights into the etiology of neurodevelopmental disorders. Mol. Psychiatry 20, 795-809. doi: $10.1038 / \mathrm{mp} .2014 .147$

Seamans, J. K., Lapish, C. C., and Durstewitz, D. (2008). Comparing the prefrontal cortex of rats and primates: Insights from electrophysiology. Neurotox. Res. 14, 249-262. doi: 10.1007/bf03033814

Sesack, S., Aoki, C., and Pickel, V. (1994). Ultrastructural localization of D2 receptor-like immunoreactivi-ty in midbrain dopamine neurons and their striatal targets. J. Neurosci. 14, 88-106. doi: 10.1523/jneurosci.14-01-00088. 1994

Shaw, P., Eckstrand, K., Sharp, W., Blumenthal, J., Lerch, J. P., Greenstein, D., et al. (2007a). Attention-deficit/hyperactivity disorder is characterized by a delay in cortical maturation. Proc. Natl. Acad. Sci. U.S.A. 104, 19649-19654. doi: 10.1073/pnas.0707741104

Shaw, P., Gornick, M., Lerch, J., Addington, A., Seal, J., Greenstein, D., et al. (2007b). Polymorphisms of the dopamine D4 receptor, clinical outcome, and cortical structure in attention-deficit/hyperactivity disorder. Arch. Gen. Psychiatry 64, 921-931. doi: 10.1001/archpsyc.64.8.921

Smiley, J. F., and Goldman-Rakic, P. S. (1993). Heterogeneous targets of dopamine synapses in mon-key prefrontal cortex demonstrated by serial section electron microscopy: a laminar analysis using the silver-enhanced diaminobenzidine sulfide (SEDS) immunolabeling technique. Cereb. Cortex 3 , 223-238. doi: 10.1093/cercor/3.3.223

Sonnenschein, S. F., Gomes, F. V., and Grace, A. A. (2020). Dysregulation of midbrain dopamine sys-tem and the pathophysiology of schizophrenia. Front. Psychiatry 11:613. doi: 10.3389/fpsyt.2020.00613

Spek, A. A., and Wouters, S. G. M. (2010). Autism and schizophrenia in high functioning adults: Behav-ioral differences and overlap. Res. Autism Spect. Dis. 4, 709-717. doi: 10.1016/j.rasd.2010.01.009

Spencer, T. J., Biederman, J., Madras, B. K., Faraone, S. V., Dougherty, D. D., Bonab, A. A., et al. (2005). In vivo neuroreceptor imaging in attentiondeficit/hyperactivity disorder: a focus on the do-pamine transporter. Biol. Psychiatry 57, 1293-1300. doi: 10.1016/j.biopsych.2005.03.036

Staal, W. G. (2014). Autism, DRD3 and repetitive and stereotyped behavior, an overview of the current knowledge. Eur. Neuropsychopharmacol. J. Eur. Coll. Neuropsychopharmacol. 25, 1421-1426. doi: 10.1016/j.euroneuro.2014.08.011

Staal, W. G., Langen, M., van Dijk, S., Mensen, V. T., and Durston, S. (2015). DRD3 gene and striatum in autism spectrum disorder. Br. J. Psychiatry 206, 431-432. doi: 10.1192/bjp.bp.114.148973

Stanford, S. C., and Heal, D. J. (2019). Catecholamines: Knowledge and understanding in the 1960s, now, and in the future. Brain Neurosci. Adv. 3:2398212818810682. doi: 10.1177/2398212818810682

Starkweather, C. K., and Uchida, N. (2021). Dopamine signals as temporal difference errors: recent ad-vances. Curr. Opin. Neurobiol. 67, 95-105. doi: 10.1016/j.conb.2020.08.014 
Steinkellner, T., Zell, V., Farino, Z. J., Sonders, M. S., Villeneuve, M., Freyberg, R. J., et al. (2018). Role for VGLUT2 in selective vulnerability of midbrain dopamine neurons. J. Clin. Invest. 128, 774-788. doi: 10.1172/jci95795

Surmeier, D. J., Obeso, J. A., and Halliday, G. M. (2017). Selective neuronal vulnerability in Parkinson disease. Nat. Rev. Neurosci. 18, 101-113. doi: 10.1038/nrn.2016.178

Tanaka, Y., Cakir, B., Xiang, Y., Sullivan, G. J., and Park, I.-H. (2020). Synthetic analyses of single-cell transcriptomes from multiple brain organoids and fetal brain. Cell Rep. 30, 1682-1689.e3. doi: 10.1016/j.celrep.2020.01.038

Tarazi, F. I., and Baldessarini, R. J. (2000). Comparative postnatal development of dopamine D1, D2 and D4 receptors in rat forebrain. Int. J. Dev. Neurosci. 18, 29-37. doi: 10.1016/s0736-5748(99)00108-2

Thomas, W. S., Neal-Beliveau, B. S., and Joyce, J. N. (1998). There is a limited critical period for dopa-mine's effects on D1 receptor expression in the developing rat neostriatum. Dev. Brain Res. 111, 99-106. doi: 10.1016/s0165-3806(98)00126-6

Tritsch, N. X., and Sabatini, B. L. (2012). Dopaminergic modulation of synaptic transmission in cortex and striatum. Neuron 76, 33-50. doi: 10.1016/j.neuron.2012.09.023

Tseng, K. Y., and O'Donnell, P. (2005). Post-pubertal emergence of prefrontal cortical up states in-duced by D1-NMDA co-activation. Cereb. Cortex 15, 49-57. doi: 10.1093/cercor/bhh107

Tseng, K.-Y., and O’Donnell, P. (2007). Dopamine modulation of prefrontal cortical interneurons chang-es during adolescence. Cereb. Cortex 17, 1235-1240. doi: 10.1093/cercor/bhl034

Uylings, H. B. M., Groenewegen, H. J., and Kolb, B. (2003). Do rats have a prefrontal cortex? Behav. Brain Res. 146, 3-17. doi: 10.1016/j.bbr.2003.09.028

Valstar, M. J., Neijs, S., Bruggenwirth, H. T., Olmer, R., Ruijter, G. J. G., Wevers, R. A., et al. (2010). Mu-copolysaccharidosis type IIIA: Clinical spectrum and genotype-phenotype correlations. Ann. Neurol. 68, 876-887. doi: $10.1002 /$ ana.22092

Verney, C. (1999). Distribution of the catecholaminergic neurons in the central nervous system of human embryos and fetuses. Microsc. Res. Tech. 46, 24-47.

Verney, C., Milosevic, A., Alvarez, C., and Berger, B. (1993). Immunocytochemical evidence of well-developed dopaminergic and noradrenergic innervations in the frontal cerebral cortex of human fetus-es at midgestation. J. Comp. Neurol. 336, 331-344. doi: 10.1002/cne. 903360303

Verney, C., Zecevic, N., Nikolic, B., Alvarez, C., and Berger, B. (1991). Early evidence of catecholaminer-gic cell groups in 5- and 6-week-old human embryos using tyrosine hydroxylase and dopamine- $\beta$ hydroxylase immunocytochemistry. Neurosci. Lett. 131, 121-124. doi: 10.1016/0304-3940(91)90351-s

Verwey, M., Grant, A., Meti, N., Adye-White, L., Torres-Berrío, A., Rioux, V., et al. (2016). Mesocortical dopamine phenotypes in mice lacking the sonic hedgehog receptor Cdon. Eneuro 3:ENEU-RO.0009-16.2016. doi: 10.1523/eneuro.0009-16.2016

Vincent, S. L., Khan, Y., and Benes, F. M. (1993). Cellular distribution of dopamine D, and D, receptors in rat medial prefrontal cortex. J. Neurosci. 13, 2251-2564. doi: 10.1523/JNEUROSCI.13-06-02551.1993

Vincent, S. L., Khan, Y., and Benes, F. M. (1995). Cellular colocalization of dopamine D1 and D2 recep-tors in rat medial prefrontal cortex. Synapse 19, 112-120. doi: 10.1002/syn. 890190207

Volkow, N. D., and Morales, M. (2015). The brain on drugs: from reward to addiction. Cell 162, 712-725. doi: 10.1016/j.cell.2015.07.046

Voorn, P., Kalsbeek, A., Jorritsma-Byham, B., and Groenewegen, H. (1988). The pre- and postnatal de-velopment of the dopaminergic cell groups in the ventral mesencephalon and the dopaminergic inner-vation of the striatum of the rat. Neuroscience 25, 857-887. doi: 10.1016/0306-4522(88)90041-3

Vosberg, D. E., Leyton, M., and Flores, C. (2020). The Netrin-1/DCC guidance system: dopamine path-way maturation and psychiatric disorders emerging in adolescence. Mol. Psychiatry 25, 297-307. doi: 10.1038/s41380-0190561-7

Walker, A. E., Spring, J. D., and Travis, M. J. (2017). Addressing cognitive deficits in schizophrenia: toward a neurobiologically informed approach. Biol. Psychiatry 81, e1-e3. doi: 10.1016/j.biopsych.2016.10.023

Wamsley, B., and Fishell, G. (2017). Genetic and activity-dependent mechanisms underlying interneuron diversity. Nat. Rev. Neurosci. 18, 299-309. doi: $10.1038 / \mathrm{nrn} .2017 .30$
Weele, C. M. V., Siciliano, C. A., and Tye, K. M. (2018). Dopamine tunes prefrontal outputs to orchestrate aversive processing. Brain Res. 1713, 16-31. doi: 10.1016/j.brainres.2018.11.044

Wei, X., Ma, T., Cheng, Y., Huang, C. C. Y., Wang, X., Lu, J., et al. (2018). Dopamine D1 or D2 receptor-expressing neurons in the central nervous system. Addict. Biol. 23, 569-584. doi: 10.1111/adb.12512 s

Weickert, C. S., Webster, M. J., Gondipalli, P., Rothmond, D., Fatula, R. J., Herman, M. M., et al. (2007). Postnatal alterations in dopaminergic markers in the human prefrontal cortex. Neuroscience 144, 1109-1119. doi: 10.1016/j.neuroscience.2006.10.009

Willems, J., de Jong, A. P. H., Scheefhals, N., Mertens, E., Catsburg, L. A. E. Poorthuis, R. B., et al. (2020). ORANGE: a CRISPR/Cas9-based genome editing toolbox for epitope tagging of endogenous proteins in neurons. PLoS Biol. 18:e3000665. doi: 10.1371/journal.pbio.3000665

Willing, J., Cortes, L. R., Brodsky, J. M., Kim, T., and Juraska, J. M. (2017). Innervation of the medial prefrontal cortex by tyrosine hydroxylase immunoreactive fibers during adolescence in male and female rats. Dev. Psychobiol. 59, 583-589. doi: 10.1002/dev.21525

Wu, J., Xiao, H., Sun, H., Zou, L., and Zhu, L.-Q. (2012). Role of dopamine receptors in ADHD: a sys-tematic meta-analysis. Mol. Neurobiol. 45, 605-620. doi: 10.1007/s12035-012-8278-5

Yamaguchi, T., Wang, H.-L., Li, X., Ng, T. H., and Morales, M. (2011). Mesocorticolimbic glutamatergic pathway. J. Neurosci. 31, 8476-8490. doi: 10.1523/jneurosci.1598-11.2011

Yan, Z., and Rein, B. (2021). Mechanisms of synaptic transmission dysregulation in the prefrontal cortex: pathophysiological implications. Mol. Psychiatry. doi: 10.1038/s41380-021-01092-3 [Online ahead of print].

Yu, Q., Liu, Y.-Z., Zhu, Y.-B., Wang, Y.-Y., Li, Q., and Yin, D.-M. (2019). Genetic labeling reveals tem-poral and spatial expression pattern of D2 dopamine receptor in rat forebrain. Brain Struct. Funct. 224, 1035-1049. doi: 10.1007/s00429-018-01824-2

Zecevic, N., and Verney, C. (1995). Development of the catecholamine neurons in human embryos and fetuses, with special emphasis on the innervation of the cerebral cortex. J. Comp. Neurol. 351, 509-535. doi: 10.1002/cne.903510404

Zeeland, A. A. S.-V., Dapretto, M., Ghahremani, D. G., Poldrack, R. A., and Bookheimer, S. Y. (2010). Reward processing in autism. Autism Res. Official J. Int. Soc. Autism Res. 3, 53-67. doi: 10.1002/aur.122

Zhang, Z.-W., Burke, M. W., Calakos, N., Beaulieu, J.-M., and Vaucher, E. (2010). Confocal analysis of cholinergic and dopaminergic inputs onto pyramidal cells in the prefrontal cortex of rodents. Front. Neuroanat. 4:21. doi: 10.3389/fnana.2010.00021

Zhong, P., Qin, L., and Yan, Z. (2020). Dopamine differentially regulates response dynamics of pre-frontal cortical principal neurons and interneurons to optogenetic stimulation of inputs from ventral tegmental area. Cereb. Cortex 30, 4402-4409. doi: 10.1093/cercor/bhaa027

Zhong, S., Zhang, S., Fan, X., Wu, Q., Yan, L., Dong, J., et al. (2018). A single-cell RNA-seq survey of the developmental landscape of the human prefrontal cortex. Nature 555, 524-528. doi: 10.1038/nature25980

Zubair, M., Murris, S. R., Isa, K., Onoe, H., Koshimizu, Y., Kobayashi, K., et al. (2021). Divergent whole brain projections from the ventral midbrain in macaques. Cereb. Cortex 31, 2913-2931. doi: 10.1093/cercor/bhaa399

Conflict of Interest: The authors declare that the research was conducted in the absence of any commercial or financial relationships that could be construed as a potential conflict of interest.

Publisher's Note: All claims expressed in this article are solely those of the authors and do not necessarily represent those of their affiliated organizations, or those of the publisher, the editors and the reviewers. Any product that may be evaluated in this article, or claim that may be made by its manufacturer, is not guaranteed or endorsed by the publisher.

Copyright (๑) 2021 Islam, Meli and Blaess. This is an open-access article distributed under the terms of the Creative Commons Attribution License (CC BY). The use, distribution or reproduction in other forums is permitted, provided the original author(s) and the copyright owner(s) are credited and that the original publication in this journal is cited, in accordance with accepted academic practice. No use, distribution or reproduction is permitted which does not comply with these terms. 